\title{
The variability and heat budget of the upper ocean under the Chile-Peru stratus
}

\author{
by Keir Colbo ${ }^{1,2,3}$ and Robert Weller ${ }^{1}$
}

\begin{abstract}
The persistent stratus clouds found west of Chile and Peru are important for the coupling of the ocean and atmosphere in the eastern Pacific and thus in the climate of the region. The relatively cool sea-surface temperatures found west of Peru and northern Chile are believed to play a role in maintaining the stratus clouds over the region. In October 2000 a buoy was deployed at 20S, $85 \mathrm{~W}$, a site near the center of the stratus region, in order to examine the variability of sea-surface temperature and the temporal evolution of the vertical structure of the upper ocean. The buoy was wellinstrumented and obtained accurate time series of the surface forcing as well as time series in the upper ocean of temperature, salinity, and velocity.

The variability and the extent to which local forcing explains the temporal evolution of upper ocean structure and heat content was examined. The sources of heating (primarily surface fluxes with weaker contributions from Ekman convergence and transport) are found to be balanced by cooling from the gyre-scale circulation, an eddy flux divergence and vertical diffusion. The deduced eddy flux divergence term is bounded away from zero and represents an order one source of cooling (and freshening). We postulate that the eddy flux divergence represents the effect of the cold coherent eddies formed near the coast, which propagate westward and slowly decay. Direct advection of coastal upwelled water by Ekman transport is negligible. Thus the upwelled water does influence the offshore structure, but through the fluctuating mesoscale flow not the mean transport.
\end{abstract}

\section{Introduction}

It is believed that the remarkably persistent stratus decks to the west of Peru and Chile (Fig. 1) exert a strong cooling influence on the local and global heat balance and, further, that they play a role in maintaining the equatorial asymmetry of sea-surface temperature (SST) and winds in the eastern Pacific (EPIC science plan). The stratus decks occur in regions of large-scale subsidence and their variability is governed by the interplay between radiative transfer, boundary-layer turbulence, surface fluxes, and cloud microphysics. They expand and contract on weekly, annual, and inter-annual time scales in response to changes in sea-surface temperature and in the temperature and velocity of the overlying air. They also follow a pronounced diurnal rhythm, with nighttime thickening and daytime

1. Physical Oceanography Department, Woods Hole Oceanographic Institution, Woods Hole, Massachusetts, 02543, U.S.A.

2. Present address: Department of Oceanography, Dalhousie University, Halifax, NS, B3H 4J1, Canada.

3. Corresponding author.email: keir.colbo@dal.ca 

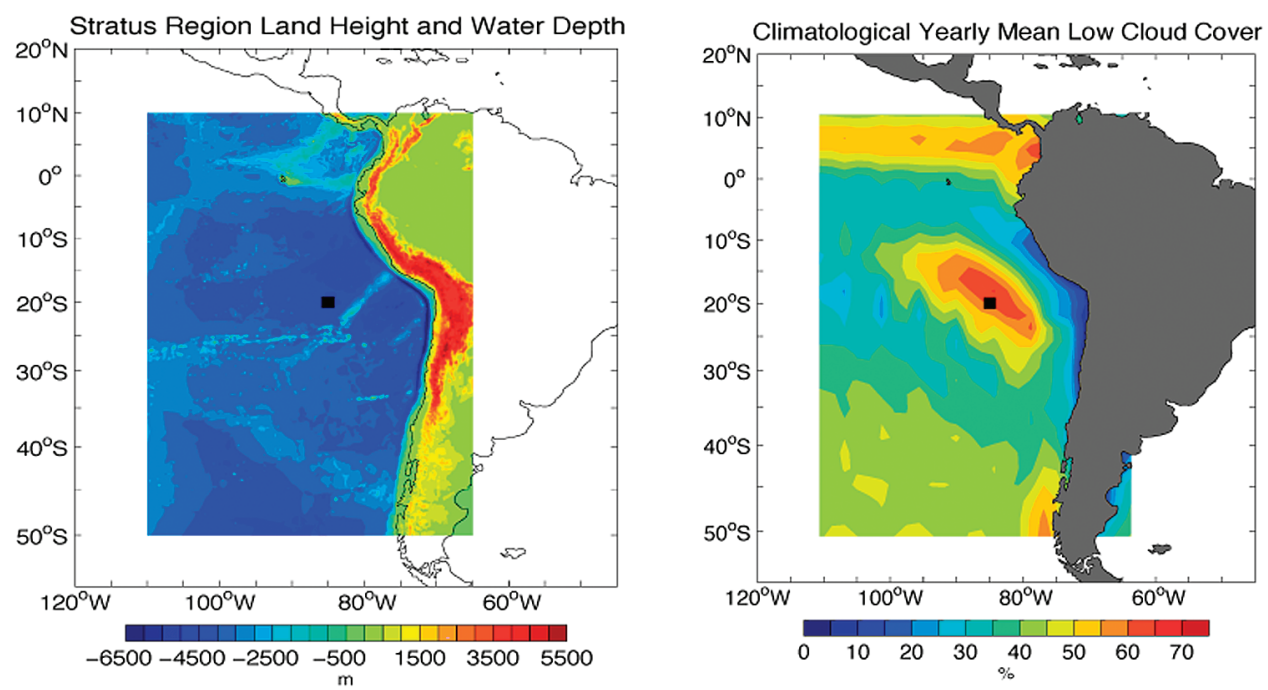

Figure 1. Ocean depth and land elevations, with a black square marking the location of the surface mooring (left). Annual mean low cloud cover contours along the west coast of South America using the NCEP reanalysis with a black square marking the location of the surface mooring (right).

thinning. There is the potential for positive feedback and the cloud deck and cool SST underneath may mutually reinforce each other through coupled fluxes.

Miller (1997) suggests that stratus clouds play an important role in modulating global warming, as they increase in response to doubled $\mathrm{CO}_{2}$ and reduce tropical warming in his studies. Unfortunately, there is little observational basis for investigation of feedback mechanisms and the role of the eastern Pacific stratus decks in climate variability, as much of our understanding comes from model studies.

Ma et al. (1996) used a coupled ocean-atmosphere GCM to contrast a control run with little stratus cloud off Peru with a run in which a stratus deck was inserted between 10 and $30 \mathrm{~S}$ east of $90 \mathrm{~W}$. This stratus deck not only lowered SST in that region by several degrees, it led to cooling along the equator in the central and eastern Pacific and to cooling south of the equator in the eastern Pacific. Yu and Mechoso (1999) continued this work, introducing temporal variability into the stratus clouds, and demonstrated an impact on the annual mean and annual signal in the SST in the eastern equatorial Pacific. They point to changes in the surface winds from off South America to over the cold tongue and consequent changes in evaporation over the cold tongue as a result of changes to the stratus clouds. Boville and Gent (1998) note that the first version of the NCAR Climate System Model (CSM-1) yielded SSTs that were up to several degrees warmer than climatology off the west coast of South America because it failed to produce enough marine stratus clouds in that region.

Our goal in this work is to develop a better understanding of the processes that control SST in the eastern Pacific under the stratus off Peru and Chile. In addition to clarifying the coupling between the SST and clouds, it is useful from the oceanographic perspective to 
understand the sources of cool water in the eastern tropical Pacific. Advection of cool water from the upwelling regions off Peru and Chile may contribute to the formation of the cold tongue. Eastward propagating equatorial Kelvin waves generate coastal sea-surface height anomalies that propagate southward along the eastern boundary of the South Pacific (Shaffer et al., 1999; Hormazabal et al., 2001). In turn, westward propagating Rossby waves generated by the sea-surface height anomalies that are not coastally trapped waves may then carry the signal off the coast (Pizarro, pers. comm.). Several analyses of satellite altimetry (e. g., Chelton and Schlax, 1996;Vega et al., 2001) provide evidence of these Rossby waves in the southeast Pacific. Thus, there may be an ENSO-related modulation of SST along the coast and offshore which may influence the stratus. Modulation of SST and chlorophyll along the coast of northern Chile during the 1996-1998 ENSO has been reported by Thomas et al. (2001).

To address this goal we deployed a well-instrumented surface mooring during the Eastern Pacific Investigation of Climate (EPIC, EPIC Science Plan, 1998) in work that is also part of CLIVAR VAMOS (the Climate Variability program's Variability in the American Monsoon Systems component). A site was chosen close to the center of the stratus cloud region and in October 2000 a surface mooring was deployed at 20S, $85 \mathrm{~W}$, some $1500 \mathrm{~km}$ off northern Chile. The site was chosen because it is representative of the offshore stratus region and is close to a site once occupied by a NOAA National Data Buoy Center (NDBC) buoy. The mooring was recovered and redeployed in October 2001, in conjunction with the EPIC 2001 Process Study. It was again recovered and redeployed in October 2002, November 2003, and December 2004, and has thus provided 4 years of data to date.

The eastern South Pacific Ocean has been little observed, especially beyond the immediate coast of South America. Historical data sets of ship observations show that the subtropical and mid-latitude southeast Pacific is among the least sampled region of the Pacific Ocean (Barnett, 1977; Goldenberg and O'Brien, 1981; Bakun and Nelson, 1991; Tourre and White, 1995). In particular, high quality observations of the ocean interior are very rare. There have been several transects in the southeastern Pacific, notably WOCE lines P18, P19, P21 and P6; however, these have not been repeated with sufficient frequency to give even inter-annual scale temporal changes. Profiling ARGO floats will help to substantially improve our climatology of the southeast Pacific Ocean (Davis, 1998), but the Lagrangian nature of the floats limits their use. The one long-term mooring in the southeast Pacific, in addition to our deployment, is the previously mentioned NDBC buoy (\#32302) deployed at 18S, 85W almost continually between February 1986 and April 1995. However, the buoy only recorded a minimal set of surface data (sea-surface and air temperature, wind speed and max wind, barometric pressure and a number of wave properties) and no subsurface data.

In this paper we use the data from the first four years of deployment (October 2000 to December 2004) to document the heat and freshwater forcing at our site. We start with a presentation of the observations and the data processing. We then proceed to a brief examination of the basic oceanography, in order to provide some context for the heat 
budget in this very data sparse region. With the goal of understanding model deficiencies, we examine the processes that dominate the annual heat (and salt) budgets. This leads to the conclusion that the eddy field plays an important role in the budgets. We then look to additional measurements to support this hypothesis of strong eddy transport. Finally, we close with a discussion of our results and some alternative hypotheses.

\section{Observational methods}

The surface mooring consists of a 3-m buoy that carries two redundant meteorological systems. Oceanographic instruments, including temperature recorders, temperature and conductivity recorders, and current meters are attached to the mooring line in the upper $450 \mathrm{~m}$.

After roughly one year on station the mooring is recovered, and two days later a new mooring is deployed. The moorings are anchored to the bottom when deployed and tracking information indicates that the surface mooring remains within a 3-km watch circle of the anchor site. The upper section of the mooring, composed of chain and plastic jacketed wire rope to which the oceanographic instruments are attached at fixed depths, remains close to vertical due to tension. The instrumental clock accuracies were checked by applying spikes (such as by immersion in an ice bath for temperature recorders) at known times both prior to deployment and just after recovery. This section presents the details of these instruments, of calibration procedures, and of their sampling.

\section{a. Moored meteorological instrumentation}

The surface buoy has 2 IMET (currently ASIMET) systems measuring air and seasurface temperatures, humidity, barometric pressure, wind speed and direction, incoming shortwave and longwave radiation, and precipitation. Thus, air-sea fluxes of heat, freshwater, and momentum can be computed from bulk formulae. One-minute averaged meteorological data are recorded internally, and hourly averages are computed and telemetered via satellite. The meteorological sensors are calibrated at WHOI prior to deployment, with that calibration being done in the lab in test chambers against standards for temperature, humidity, and pressure and on the roof against transfer standards for incoming shortwave and longwave radiation. In addition, to verify that installation on the buoy did not alter performance, the fully instrumented buoy was assembled, proper performance of the anemometer's compass verified, and the system was run outside at WHOI near reference sensors for more than a month. Once the buoy is deployed, the ship is positioned about 300 to $500 \mathrm{~m}$ downwind, bow into the wind for at least 24 hours to do an inter-comparison with shipboard meteorological sensors as an in-situ check on the buoy sensors. This same comparison is repeated just prior to recovery. After recovery, the sensors are returned to WHOI for post-deployment calibration.

The IMET sensors used on these deployments are described in Table 1. The discus buoy upon which the sensors are mounted is equipped with a vane so that it keeps a fixed orientation to the wind, allowing sensors which need uncontaminated air flow to be 
Table 1. The standard suite of sensors composing the IMET package is shown (two of each are mounted on the buoy superstructure). Heights shown are representative measurements from a single deployment. Variation from year-to-year is within $5 \mathrm{~cm}$. Accuracies are for the annually averaged field, as discussed in Colbo and Weller (2008).

Instrument

Measurement

Wind speed

Wind direction

Air temperature

Relative humidity

Barometric pressure

Longwave radiation

Shortwave radiation

Precipitation

Sea surface temp.

\section{manufacturer}

R.M. Young 5103

R.M. Young 5103

Rotronic MP-100F

Rotronic MP-100F

AIR DB1A or DB2A

Modified Eppley PIR

Eppley PSP

R.M. Young 50201

SBE-39

$$
\text { Nominal height (m) }
$$

2.97

2.97

2.57

2.57

2.37

3.16

3.16

2.73

$-1.0$
Accuracy

$0.15 \mathrm{~m} / \mathrm{s}$

$5 \mathrm{deg}$.

$0.1 \mathrm{~K}$

$1 \%$

$0.2 \mathrm{mb}$

$4 \mathrm{~W} / \mathrm{m}^{2}$

$5 \mathrm{~W} / \mathrm{m}^{2}$

$\mathrm{N} / \mathrm{A}$

$0.04 \mathrm{~K}$

properly positioned. Humidity and air temperature sensors are protected from sunlight by passive, multi-plate radiation shields and from salt contamination by porous Teflon filters. Due to battery limitations, air temperature and humidity are naturally ventilated. Radiometers are located high enough to be out of the shadow zone of other instrumentation.

An independent observation of rainfall was made on Stratus 1,2 and 3 by an acoustic range gauge provide by Jeff Nystuen (UW APL), located between 23.5 and $50 \mathrm{~m}$ depth on the different deployments. This instrument records ambient noise at frequencies where the source of the noise is dominated by bubbles created by raindrops falling on the sea surface.

Conservative estimates of the accuracies are found in Table 1 and have been developed based on the pre and post-deployment calibrations, on comparison of the two concurrent sets of time series from the buoy, and from the ship-buoy comparisons. These comparisons have benefited from participation on the cruises by J. Hare and C. Fairall of the NOAA Environmental Technology Laboratory, as their group equipped the vessel with additional high quality meteorological and flux sensors. A more comprehensive examination of accuracies for the IMET instrumentation can be found in Colbo and Weller (2008).

\section{b. Ocean data processing}

The mooring is equipped with two primary types of velocity instrumentation: An RDI $300 \mathrm{kHz}$ acoustic Doppler current profiler (ADCP), and several vector measuring current meters (VMCMs). The ADCP uses the time difference between the return signal of two acoustic pulses to calculate the velocity of a backscatterer along a beam path, and presumably the surrounding water. Multiple beams are combined, assuming spatially homogeneous flow, to provide a vertical profile of the three components of velocity. The VMCM uses two pairs of rotors at right angles to each other to measure horizontal flow at a single depth. Sampling intervals ranged from 1 minute to 7.5 minutes for the VMCMs and between 30 minutes to 1 hour for the ADCP. In addition a variety of non-profiling acoustic 
instruments manufactured by Sontek, Aanderaa and Nortek have been tested. The accuracy of these instruments in the near-surface wave field, and on a moving mooring line has yet to be determined to our satisfaction, but the lack of moving parts subject to fouling is desirable in a region frequented by long-line fishing boats. Three of the VMCM propeller instruments were fouled by fishing line during the third year of deployment.

The VMCMs gave good data throughout the whole deployment, with only about $1 \%$ of the data missing in small intermittent patches (except for fishing line fouling in year 3). These were all interpolated through to give a complete record. The near-surface $(10 \mathrm{~m}$ and $20 \mathrm{~m}$ ) VMCMs do not appear to have been affected by bio-fouling, although there is certainly growth on the surrounding cage. Comparison of spectra from the first and last month of deployment are statistically similar. The VMCMs compute vector-averaged velocity components and accumulate the averages over the sample interval. Older VMCMs with tape recorders were set up to record once every 7.5 minutes. New VMCMs with solid state recorders were set to record every 1 minute.

The ADCP data record required more post-processing than the VMCM data. Nearsurface bins $(<50 \mathrm{~m})$ sometimes suffered from a lack of strong backscatterers, causing the signal return strength to drop and the recorded velocity to become unreliable. This is a common problem in near-surface waters, and is often attributed to the diurnal migration of zooplankton, causing the return signal strength to fall off during the day and return during the night time. The lower eight bins, centered at depths between $128 \mathrm{~m}$ and $58 \mathrm{~m}$, suffered only minor data loss $(<2 \%)$, and were filled with interpolation to provide complete records. Bin 9, at $48 \mathrm{~m}$ depth, was initially missing about $13 \%$ of its data. Careful interpolation reduced this to about $5 \%$, largely centered in two main periods. Higher depth bins will not be used. The ADCP in the second deployment failed half way during the year, probably due to faulty power consumption, but was otherwise similar in data quality to the other three years.

The mooring line was instrumented with a variety of temperature/salinity (SeaBird Electronics SBE-16s and SBE-37s) and temperature only (SeaBird Electronics SBE-39s and Richard Brancker temperature pods) instrumentation. Instrumentation was spaced more closely in the upper water column with progressively greater spacing with depth, with the deepest instrument at $450 \mathrm{~m}$. All the instruments recorded internally at intervals of 3.75 to 30 minutes. The data return was uniformly good with only a couple instrument failures.

All temperature sensors were calibrated in water baths at WHOI before and after deployment. SeaBird instruments were calibrated by the manufacturer before and after deployment. Calibration drifts with all the temperature and conductivity sensors were minimal.

Two-day gaps exist in the velocity and temperature records during mooring recovery and deployment. The velocity gaps were filled with a combination of a tidal fit plus a spline to the low frequency signal at each depth. The velocity fields are also corrected for the motion of the buoy as it moves around within its watch circle. This is typically negligible, with maximum velocities of $\approx 2 \mathrm{~mm} / \mathrm{s}$ for periods of several days. Gaps in the temperature and salinity fields were filled by a spline fit to the low-frequency signal. 


\section{c. Surface fluxes}

Surface fluxes of heat, momentum, and salt are calculated based upon bulk formula as described in Weller and Anderson (1996) and using version 2.6 of the COARE algorithms. For flux calculations, the temperature measurement at $1 \mathrm{~m}$ is used to calculate the skin temperature following Fairall et al. (1996). Net shortwave flux is based upon a varying albedo as described by Payne (1972). Net longwave flux is computed by subtracting the estimated outgoing longwave, $\mathrm{LW} \uparrow=\varepsilon \sigma \mathrm{T}^{4}+(1-\varepsilon) \mathrm{LW} \downarrow$, from the measured incoming radiation, where $\varepsilon=0.97$ is the emissivity and $\sigma$ is the Stefan-Boltzmann constant. Freshwater flux is derived from the measured precipitation rate, an estimated drizzle rate and the inferred evaporation corresponding to the latent heat flux. Estimated accuracy of the annual mean values of the air-sea fluxes are: sensible heat $\left( \pm 1.5 \mathrm{~W} / \mathrm{m}^{2}\right)$, latent heat $\left( \pm 5 \mathrm{~W} / \mathrm{m}^{2}\right)$, net shortwave radiation $\left( \pm 5 \mathrm{~W} / \mathrm{m}^{2}\right)$, net longwave radiation $\left( \pm 4 \mathrm{~W} / \mathrm{m}^{2}\right)$, net heat $\left( \pm 8 \mathrm{~W} / \mathrm{m}^{2}\right)$, wind stress $\left( \pm 0.007 \mathrm{~N} / \mathrm{m}^{2}\right)$. Instantaneous errors are larger, but are reduced through averaging. A detailed description of the meteorological and flux errors can be found in Colbo and Weller (2007).

\section{Upper ocean variability}

The historical data set for the region around our mooring is quite limited, and so it is instructive to first examine some of the basic oceanographic features of the site.

\section{a. Upper ocean temperature and salinity}

The water column at the mooring site consists of a strongly stratified temperature profile with a permanent thermocline starting between $130-150 \mathrm{~m}$ (Fig. 2). Whereas the temperature profile is stable, the salinity is not, with the consequence that the permanent thermocline is subject to double diffusive instabilities (salt fingering). Below the thermocline, with a maximum at about $170-200 \mathrm{~m}$, there exists a strong salinity minimum associated with equatorward flowing, mid-latitude surface water that has been subducted. There follows a slight increase in salinity, and then much deeper, at about $700 \mathrm{~m}$, one finds a secondary salinity minimum associated with Antarctic Intermediate Water (Tsuchiya and Talley, 1998). The temperature profile does not show any clear indication of the water masses that are shown in the salinity profile. Similarly, density below the thermocline is strongly temperature dependent and shows little indication of water mass variability. We also notice some pronounced variability in salinity above the thermocline that is largely compensated by temperature. This spiciness was apparent in many of the CTD casts from the mooring recovery and deployment cruises. These cruises have traditionally taken place in austral spring, shortly after the period of deepest surface ventilation, and so the spiciness may be larger than at other times of the year. The two CTD casts in Figure 2 were chosen so as to bracket the observed variability (which is dominated by high frequency internal waves) in the thermocline during austral spring.

The CTD profiles represent a snapshot from a particular time of year. To understand the temporal evolution we need to examine the mooring line observations. Figure 3 shows the 


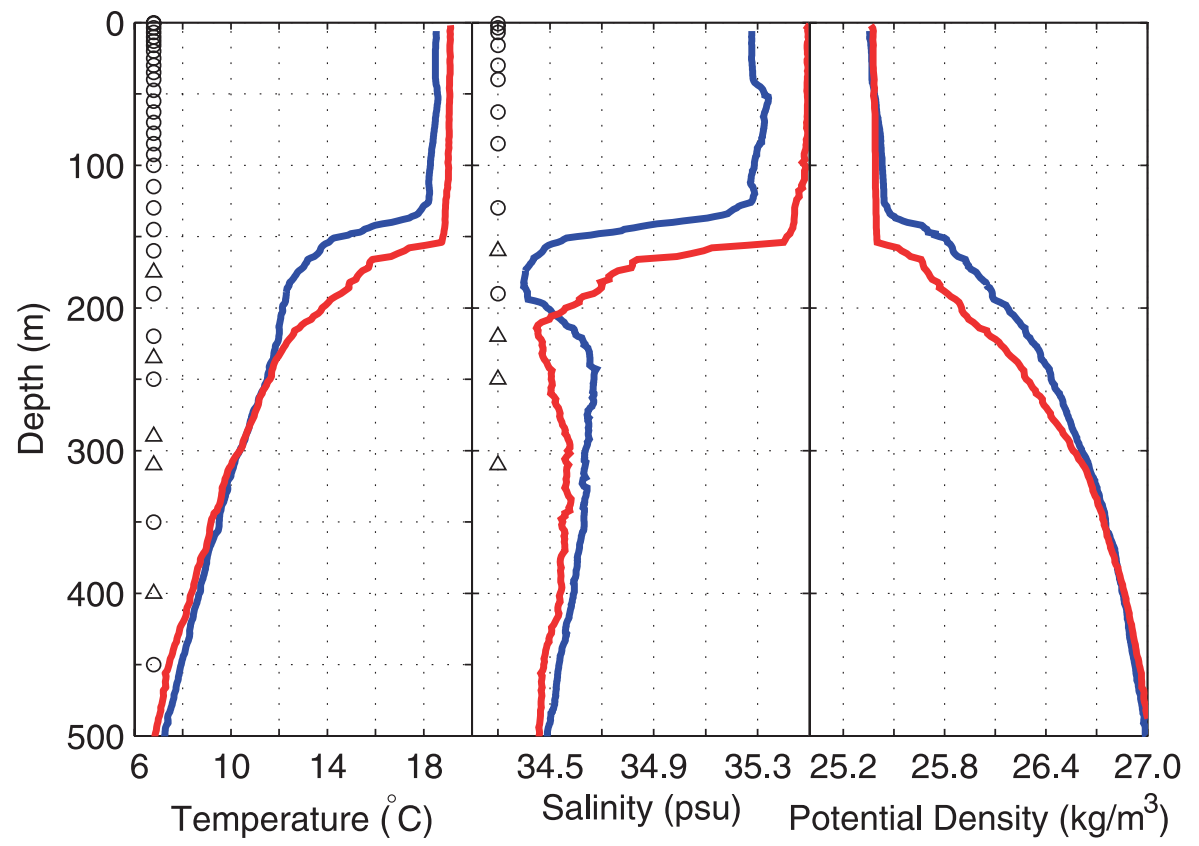

Figure 2. CTD casts from October 18, 2001 (blue) and October 9, 2000 (red). For reference, the circles indicate the location of temperature (left) and salinity (middle) instrumentation on the mooring line. Supplemental instrumentation for Stratus 4 onward is shown by triangles.

monthly mean temperature structure for the first 4 years of data. We see that the water column is ventilated down to the thermocline in late austral winter to early austral spring, and is capped by a shallow seasonal thermocline from austral summer through austral fall at which point the mixed layer depth is typically less than $50 \mathrm{~m}$. An annual cycle in the thermocline depth is also apparent. This is probably due to the annual variation in coastal winds generating a Rossby wave (Bigg and Gill, 1986; Vega et al., 2001). The thermocline motion is also consistent with an observed phase lag between the Ekman downwelling and the equatorward Sverdrup transport. However, we are unaware of a physical process that would allow such a seasonal lag.

The daily averaged temperature anomalies about the interpolated monthly mean state, for the first four years of data and for selected instrument depths, are shown in Figure 4. The large variations at depths from 100 to $200 \mathrm{~m}$ dominate the figure. To account for the stronger gradients at these depths we show the standard deviation of the implied isotherm displacements on the right. We can still see a maximum at the top of the thermocline, but the surface variability is also evident. Spectra of the temperature anomalies (not shown) show that the surface variability has a much larger annual signal than at depth. Thus a large fraction of the implied near-surface isothermal displacement is due to inter-annual variability in surface fluxes.

At this latitude, high frequency coastal sea-surface height anomalies (such as those 


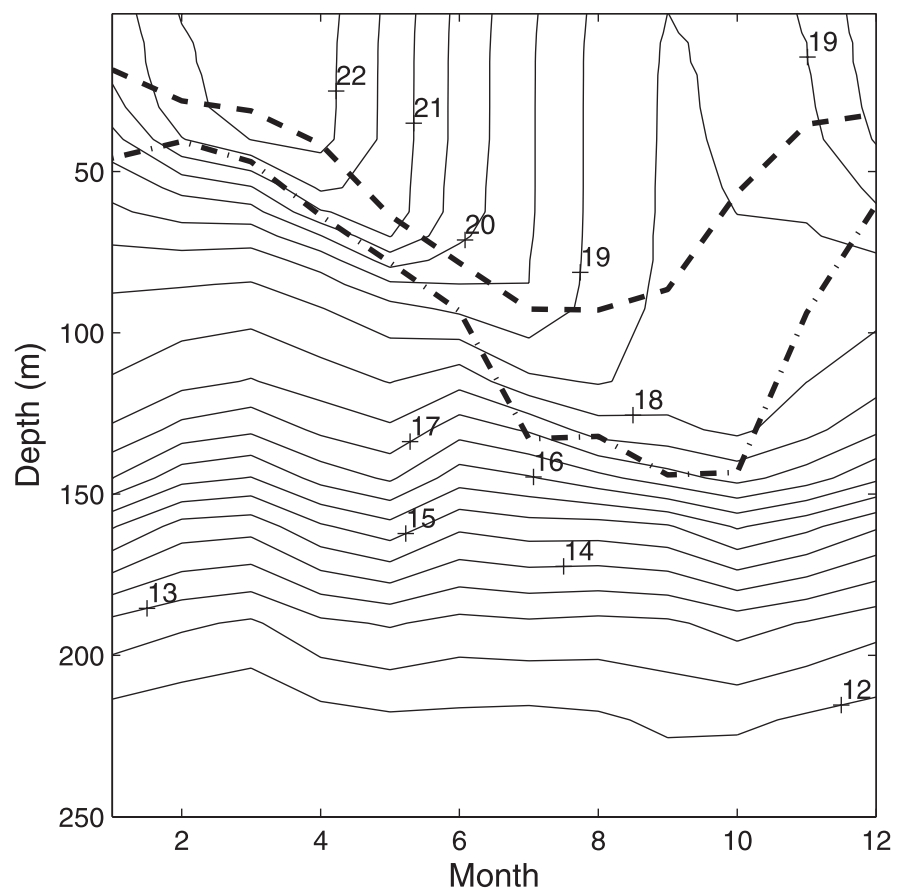

Figure 3. The monthly mean temperature climatology as derived from the first 4 years of data (October 2000 - December 2004). Overlaid are the mean (dashed) and maximum (dash-dot) nocturnal mixed layer depths (based on a $0.1 \mathrm{~K}$ criterion).

generated by Madden-Julian Oscillations) are coastally trapped (Grimshaw and Allen, 1988). Thus Rossby waves generated by coastal sea level height anomalies are not responsible for the higher frequency motion of the thermocline. We will show that these energetic thermocline displacements are due to mesoscale eddies that were formed near the coast and then propagate westward at Rossby wave speeds. There is also occasional variability on short time scales evident in the temperature and salinity records. Variations of up to $\pm 0.3 \mathrm{psu}$ and $\pm 0.8^{\circ} \mathrm{C}$ within less than a day are observed in waters below the mixed layer, indicating that there is frontal activity in the area. Some of these fronts can be clearly seen in the winter mixed layers of Figure 4.

\section{b. Upper ocean velocity}

Progressive velocity vectors for the first 18 months of data (up until the ADCP failed in year 2) are plotted in Figure 5. We first note that the velocity at $130 \mathrm{~m}$, roughly the top of the thermocline, shows a general trend to the north northwest with substantial variability due to the local eddy field. The long term mean flow at this depth is equatorward as would be expected in this portion of the gyre. There are little data with which to compare our observed velocity. Tsuchiya and Talley (1998) show steric height calculated for the P19 WOCE line (at $88 \mathrm{~W}$ ). However, comparing a single hydrographic transect with an annual 


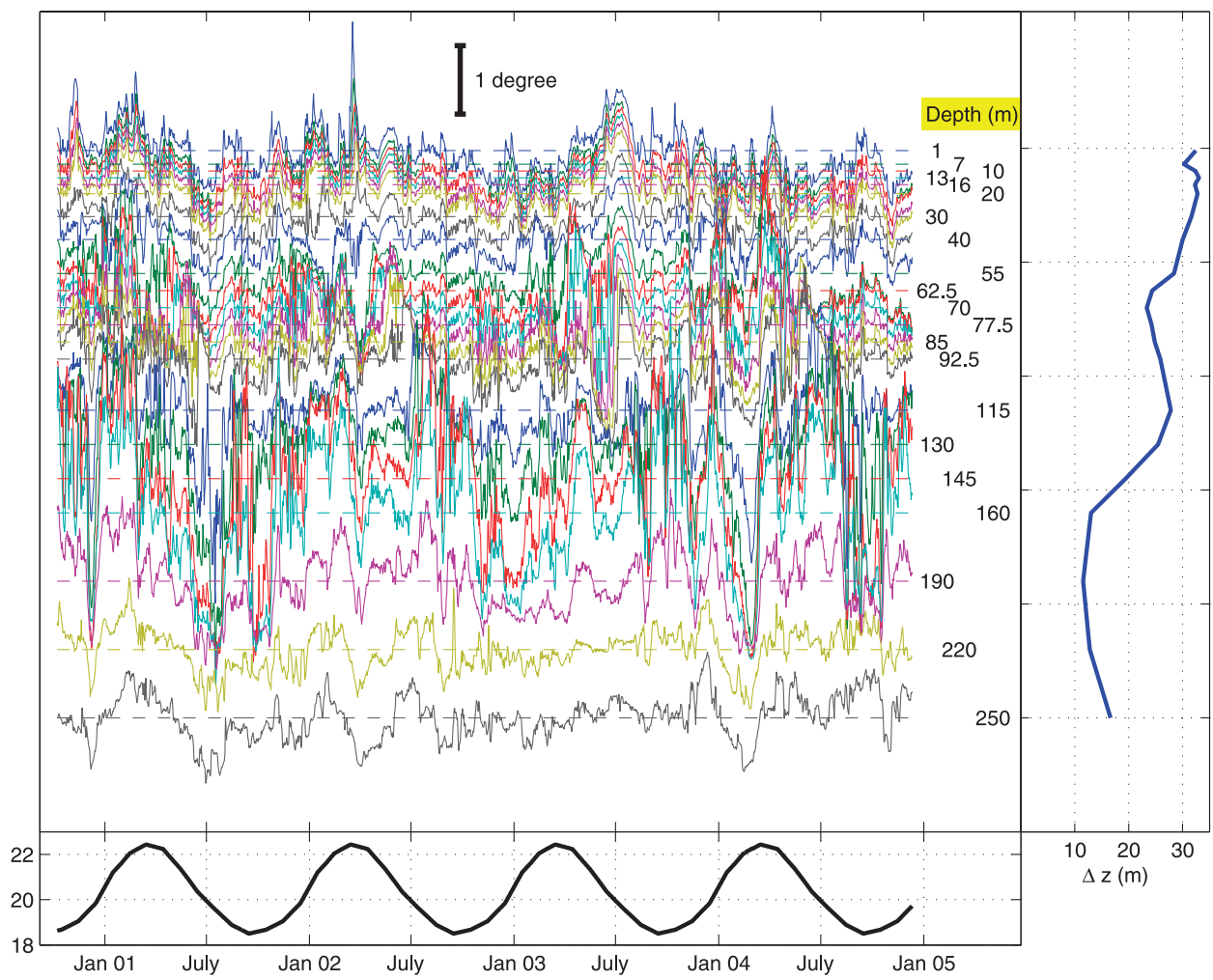

Figure 4. The temperature anomaly (from the 4-year monthly mean) for selected instrument depths (labeled on the right). Successive temperature anomaly traces have been offset in the vertical by an amount proportional to the instrument spacing. For reference the annual cycle of SST is indicated at the bottom (different vertical scale). The inset on the right shows the standard deviation of the inferred isotherm displacements.

mean is not useful. Johnson and McPhaden (1999) show acceleration potential on two neutral density anomaly surfaces $\left(\gamma_{n}=25\right.$ and $\left.26.5 \mathrm{~kg} / \mathrm{m}^{3}\right)$. Their figure stops at $20 \mathrm{~S}$, but indicates a stronger zonal flow component than is observed (i.e. their flow is oriented more toward the northwest rather than the north).

Although we lack sufficient resolution in the upper ocean to examine the Ekman layer, we have plotted an estimate of the mean velocity in the Ekman layer. This was determined from the measured wind stress and used the climatological monthly mean mixed layer depths (calculated from the 4 years of data) as a proxy for the depth of the Ekman transport layer. We note that the magnitude of the implied velocity seems sensible, and the structure is not unlike that seen in other experiments (e.g. LOTUS, see Schudlich and Price, 1998).

The progressive vector plot gives a good sense of the low-frequency flow but not the higher frequencies. Velocity and shear rotary spectra are shown in Figure 6. Spectra of all the velocity sensors above the thermocline show pronounced semi-diurnal, diurnal and 


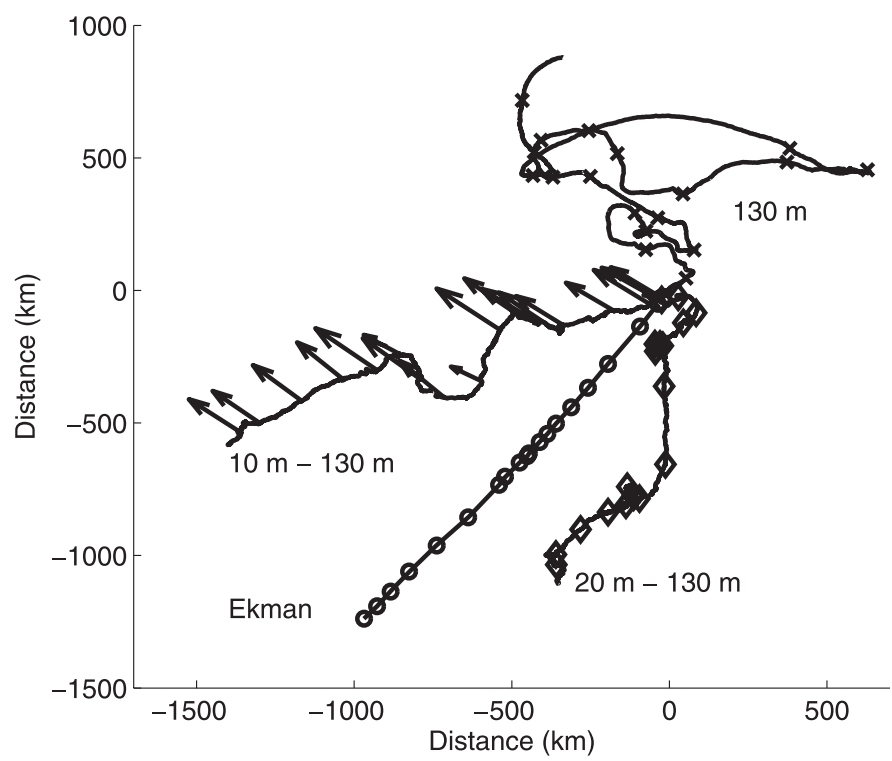

Figure 5. Progressive velocity vectors at $130 \mathrm{~m}$ (crosses), $10 \mathrm{~m}$ relative to $130 \mathrm{~m}$ (arrows) and $20 \mathrm{~m}$ relative to $130 \mathrm{~m}$ (diamonds) for the first 18 months of data. The arrows show the monthly mean winds, and the symbols on the other curves are spaced a month apart. Also shown is the inferred mean velocity of the Ekman layer (circles) based upon the observed winds and the climatological mixed layer depth (see Fig. 3).

inertial peaks. Cyclonic velocity (and shear) is substantially elevated above the level of anticyclonic velocity. Shear spectra are also predominantly cyclonic, and are typically most energetic in the inertial band. The lack of an inertial peak in the shear spectra between 10 and $20 \mathrm{~m}$ (red curve) indicates that this layer typically moves as a slab at these frequencies. The strong diurnal peak is probably due to mild changes in stratification with the diurnal cycle of surface heating.

\section{c. Heat and salt budgets}

As mentioned in the earlier section there is a substantial flux of heat and salt into the surface of the ocean at our mooring site. These fluxes need to balance on some appropriately long time scale. Because of the frontal activity near our mooring, assessing the heat budget on short time scales is difficult due to the large unpredictable advective component. However, on an annual time scale the passage of these fronts over our mooring site should average out of the heat budget. These fronts are not associated with the cold core eddies, since they have no significant signature in either thermocline depth or velocity. Their temperature (and salinity) signature is variable in depth, but rarely reaches and never extends below the thermocline. We thus seek to quantify the terms in the annual budgets of heat and salt. We shall start with a detailed explanation of the heat budget and in the next section present observational estimates of each of the terms. 

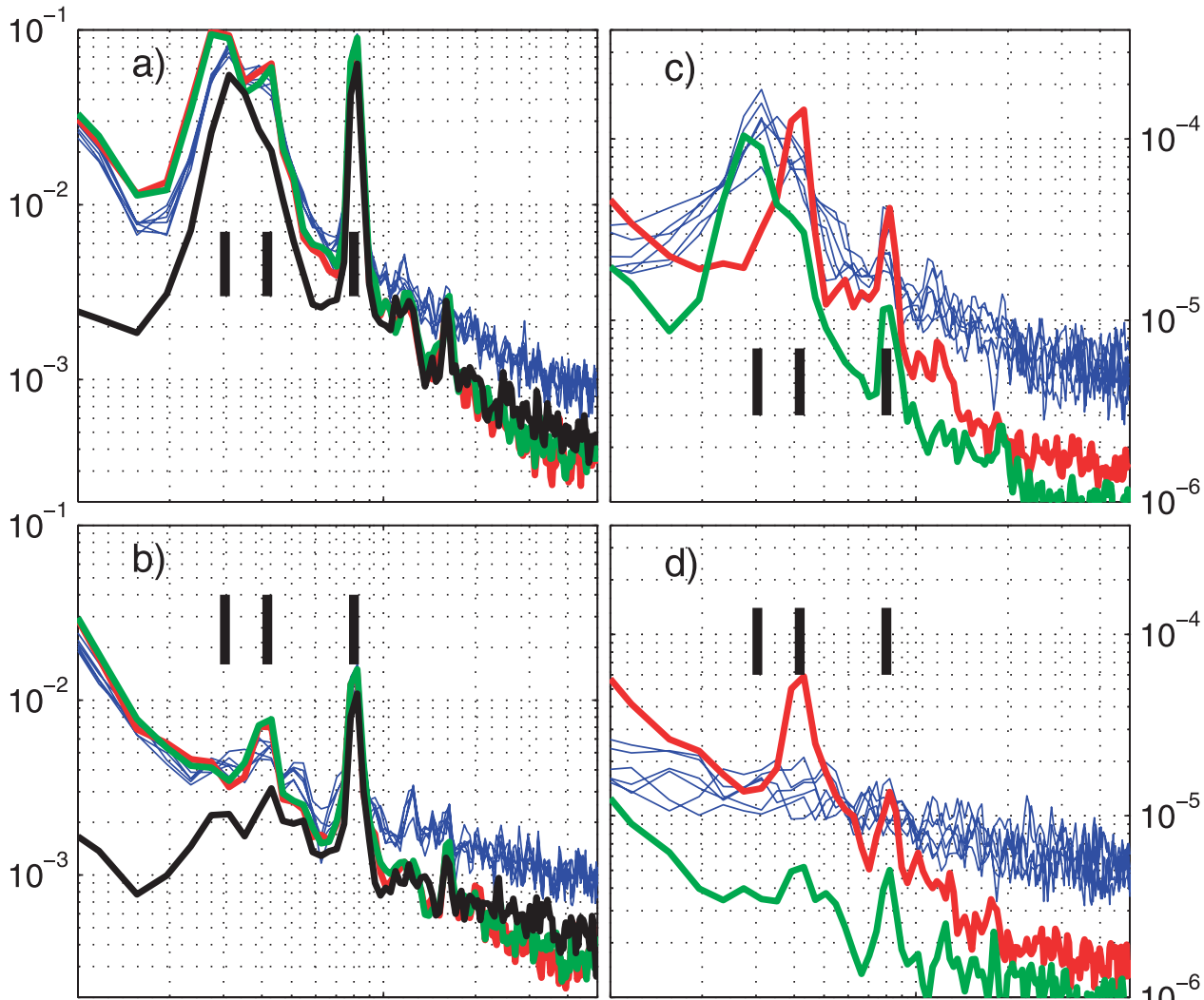

d)

$10^{-2}$

$10^{-1}$

Frequency (cph)

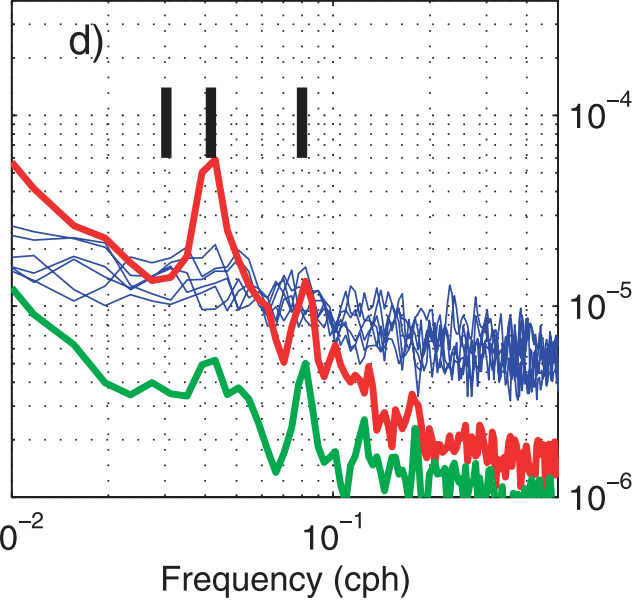

Figure 6. Rotary spectra of velocity (cyclonic (a), anticyclonic (b)) and shear (cyclonic (c), anticyclonic (d)). The velocity spectra are at $10 \mathrm{~m}$ (red, VMCM), $20 \mathrm{~m}$ (green, VMCM), 128 to $68 \mathrm{~m}$ (blue, ADCP) and $350 \mathrm{~m}$ (black, VMCM). Shear spectra are calculated between 10 and $20 \mathrm{~m}$ (red), 20 and $68 \mathrm{~m}$ (green), and 68 to $128 \mathrm{~m}$ in ten meter increments (blue). Solid black lines indicate the location of the Coriolis, the diurnal and the semi-diurnal frequencies.

The heat equation integrated over the year and down to some depth, $z_{0}$, is

$$
\begin{array}{r}
\int_{0}^{1 \text { year }}\left(\frac{Q_{\text {net }}}{C_{P} \rho_{0}}-\int_{z 0}^{0}\left(u \cdot \nabla T+w_{E} \frac{d T}{d z}+\frac{d \overline{u^{\prime} T^{\prime}}}{d x}+\frac{d \overline{v^{\prime} T^{\prime}}}{d y}\right) d z-\left.\kappa_{v} \frac{d T}{d z}\right|_{z=z 0}\right) d t \\
=\int_{0}^{1 \text { year }} \int_{z 0}^{0} \frac{\partial T}{\partial t} d z d t
\end{array}
$$

where $Q_{n e t}$ is the net surface heat flux, $C_{P}$ is the specific heat of seawater, $\rho_{0}$ is the density, $w_{E}$ is the Ekman pumping velocity, $\overline{u^{\prime} T^{\prime}}$ and $\overline{v^{\prime} T^{\prime}}$ are the eddy correlations of velocity and 
temperature, and $\kappa_{\mathrm{v}}$ is the vertical eddy diffusivity. In the above equation, we have assumed that the only important horizontal convergence of velocity, and hence heat, is due to the wind-driven Ekman transport. This is motivated by two factors. The first is that this is likely to be the dominant contributor to large-scale horizontal convergence near our mooring site. The second is that we have no good means of estimating the convergence or divergence in the quasi-geostrophic flow. We will attempt to put a bound on this missing term in the discussion.

We first need to consider the volume that we are going to integrate over in the heat, and later salt, budgets. We shall choose a depth well below the thermocline since the diffusive flux acting on the weak gradients at depth will be small. However, this requires that we be more careful with the vertical variation of the advective component. We will examine other choices for the depth of integration in the discussion.

The first term can be evaluated from the surface meteorology at very high temporal resolution. In evaluating the advective component, we shall assume that it can be divided into an Ekman and a geostrophic component. The Ekman transport will be evaluated from weekly averaged QuikScat satellite wind fields and combined with weekly averaged satellite derived sea-surface temperatures to produce $U_{E} \cdot \nabla T_{S S T}$. One could argue whether SST gradients, as opposed to mixed layer gradients, are advected by the Ekman transport but this seems unnecessarily complex for the current work. The geostrophic component is more difficult to estimate since we can neither derive absolute geostrophic velocity fields from satellite data (although GRACE and future missions show promise in this regard), nor do we have a method of measuring temperature gradients below the mixed layer. Instead we will use vertical profiles of temporally averaged velocity to define a length scale for the quasi-geostrophic flow, and estimate horizontal gradients of temperature from historic data.

The profile of the Ekman pumping velocity will be obtained from the moored velocity data under the assumption of Sverdrup dynamics. The eddy flux divergence is a particularly difficult term to measure. We shall therefore calculate it as a residual of the equation. This calculated flux is checked for consistency against additional measurements. For instance, we can use some simple arguments to derive a possible flux divergence from the point measurements of eddy flux at the mooring site. Satellite and drifter data will also be use to indicate the importance of the eddy field. Finally, the vertical diffusivity is calculated using the observed temperature profile and an assumed vertical diffusivity.

The right-hand side of the equation will be approximately equal to zero on annual time scales, modified by inter-annual fluctuations in the heat content of the ocean. One way to examine this would be to consider the slope of a best fit line to the temperature anomaly plots in Figure 4. At none of these depths is the slope significantly different from zero at a $50 \%$ confidence interval. The maximum slope is at the surface and corresponds to $-0.2 \mathrm{~K} /$ year, between 50 and $200 \mathrm{~m}$ the slopes are very small, and at $250 \mathrm{~m}$ the slope is $+0.1 \mathrm{~K} /$ year. A pessimistic choice would thus be a $0.3 \mathrm{~K}$ change for all the water above the thermocline. This would lead to a change in heat content of $\approx 45^{\circ} \mathrm{C} \mathrm{m}$ given a $150 \mathrm{~m}$ deep 


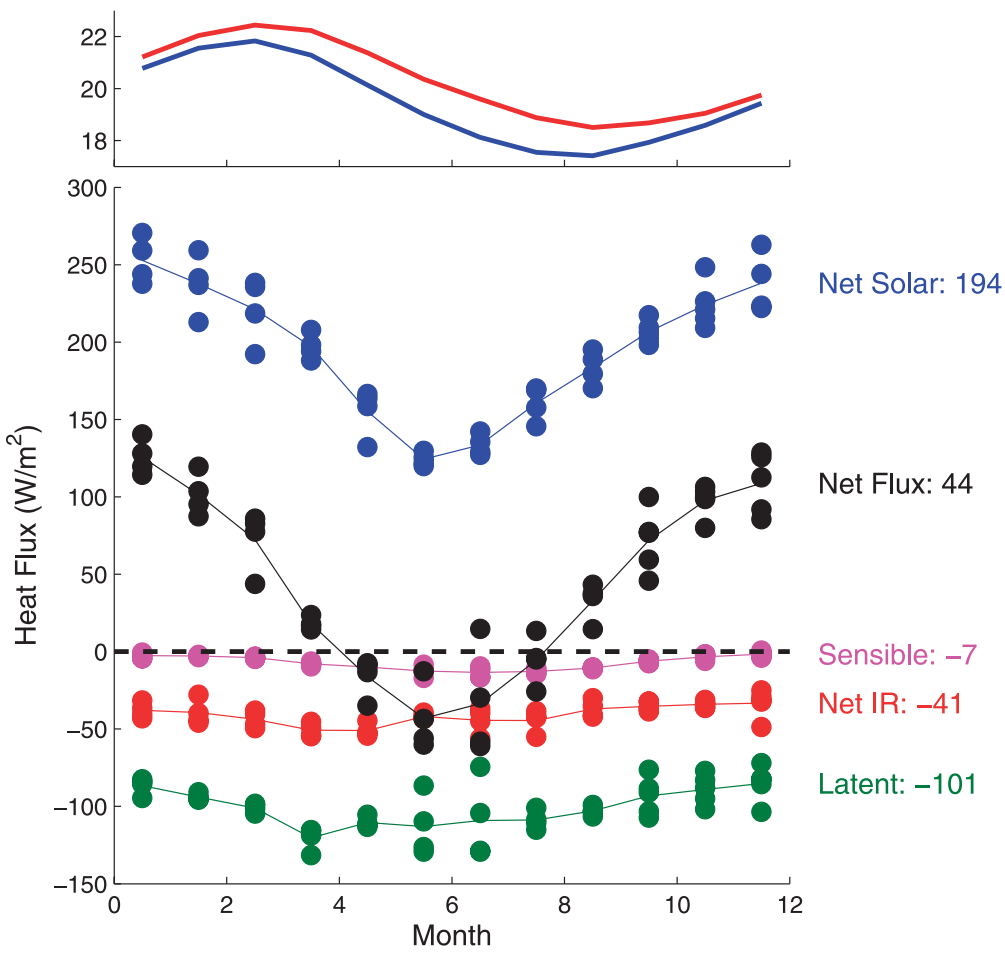

Figure 7. Surface heat fluxes (lower panel), and the air (blue) and sea-surface (red) temperatures (upper panel) for four years of data. The heat flux components show monthly averages (dots), the multi-year mean (line) and are labeled with the corresponding four year annual average value on the right (in $\mathrm{W} / \mathrm{m}^{2}$ ).

thermocline. This is equivalent to an additional surface heat flux of $5-6 \mathrm{~W} / \mathrm{m}^{2}$. We will therefore assume that the right-hand side of equation 1 is equal to $0 \pm 6 \mathrm{~W} / \mathrm{m}^{2}$.

\section{Annual budgets}

The heat (and later salt) budget will be estimated from the available data. The errors inherent in the measurements and assumptions will be quantified, and the terms will each be presented as a mean estimate with a $90 \%$ error bar.

\section{a. Surface fluxes}

The monthly mean heat fluxes, as well as the monthly values of air and sea-surface temperature are shown in Figure 7 . The 4 years of data show good agreement with some minor spread. The 3-year average net heat flux is $44 \pm 5 \mathrm{~W} / \mathrm{m}^{2}$, which if unbalanced would lead to a net warming of water above the thermocline by $2.4^{\circ} \mathrm{C}$ per year. Alternatively, this input of heat could deepen the thermocline by about $45 \mathrm{~m}$ per year. The uncertainty is 
based upon a $90 \%$ confidence limit of $\pm 8 \mathrm{~W} / \mathrm{m}^{2}$ for a single annual mean net heat flux (Colbo and Weller, 2007).

We note that the radiative fluxes show little variability in the winter, when there are persistent clouds. However the wintertime latent heat can show large variability. Surprisingly, the variability tends to take the form of pronounced periods of low wind speed in the Trade winds instead of higher wind speed synoptic storm activity.

The latent heat flux corresponds to an annual rate of evaporation of $1.3 \pm 0.1 \mathrm{~m}$. The precipitation rate is negligible in these oceanic deserts, with an annual value of $0.025 \pm$ $0.005 \mathrm{~m}$ (as measured by a pair of R.M. Young siphon gauge and a subsurface acoustic gauge). This leads to a considerable input of salt into the upper ocean every year. Although there is substantial drizzle associated with stratus clouds, very little of the water makes it to the sea surface before evaporating. Estimates of the drizzle reaching the surface are difficult to make but are generally less than $0.5 \mathrm{~mm} /$ day (Comstock et al., 2005). Consequently, drizzle contributes a greater freshwater input than measurable rain, with an annual rate of $0.15 \pm 0.05 \mathrm{~m}$. Thus the surface flux of salt is $40 \pm 6 \mathrm{psu} \mathrm{m} / \mathrm{year}$. Over a $150 \mathrm{~m}$ deep surface layer, the salinity would increase by $0.27 \mathrm{psu} / \mathrm{year}$.

Aside from the need to balance these surface fluxes, we can see that the temporal gradient of the sea-surface temperature is slightly out of phase with the net surface heat flux, indicating that other processes are important contributors to the heat and salt budgets.

There is also a transfer of momentum across the air-sea boundary due to the wind. The mooring is located slightly south of the center of the Trade wind jet and so the wind field is moderate in strength. The 4-year average stress from the mooring data is $\tau_{\mathrm{avg}}=$ $0.076 \mathrm{~N} / \mathrm{m}^{2}$. It is also relatively uniform in direction (see Fig. 5). In fact $80 \%$ of the hourly averaged wind vectors are oriented to within $20^{\circ}$ of the 4-year averaged wind vector (oriented at $305^{\circ}$ ). This does not mean that there is not variability in the wind magnitude, the winds do weaken and strengthen as the Trade wind jet moves north and south, but the orientation is largely fixed. This can be expressed by the steadiness (ratio of vector average to scalar average winds) which is 0.79 for the one minute data and 0.93 for the hourly averages.

\section{b. Ekman transport}

Although we could measure Ekman transport at the buoy directly from the wind measurements, we feel it is more instructive to use the QuikScat satellite wind field for two reasons. The first is that we need to estimate the convergence in the Ekman transport at our mooring in order to get the Ekman pumping velocity, $w_{E}$. Additionally, we are interested in the representativeness of our mooring location, and so would like to generate a broad map of the Ekman heat transport. To go with the wind coverage, we need spatial temperature maps. We shall use the Tropical Rainfall Measuring Mission Microwave Imager (TMI) SST fields at one quarter degree and weekly resolution. TMI fields are clearly superior to the primary alternative, Reynolds OI SST (Reynolds et al., 2002), because of the microwave imagers ability to see through the persistent cloud cover. Additionally, the broad spatial smoothing of the Reynolds field is undesirable. 
Both TMI and QuikScat winds compare favorably to the buoy measurements. TMI is necessarily smoother than the buoy SST data, since it doesn't resolve either the small-scale temporal or spatial gradients that the buoy observes. However, daily TMI is usually within $0.1^{\circ} \mathrm{C}$ of the buoy daily average and shows no noticeable seasonal or linear bias. QuikScat winds show surprisingly little deviation from the observations as well. We deduce that this is primarily due to the incredible steadiness of the wind field at the buoy. QuikScat weekly averaged fields are within $10 \%$ of the buoy measurements, when the buoy speeds are corrected to 10-m height.

We will use QuikScat Level 3 daily, gridded ocean wind vectors. This consists of the vector wind fields for each ascending and descending path mapped onto a global $0.25^{\circ} \times$ $0.25^{\circ}$ grid. Because the satellite does not see every point every day, and to eliminate some of the small-scale graininess, and for comparison with the SST fields, we will form weekly averages of all the ascending and descending tracks. In practice, this gives between 5-12 wind measurements for each quarter degree grid box per week. There may be some question about aliasing of diurnal wind signals by the ascending and descending tracks, but we believe that this would be a small effect.

The weekly averaged winds at a quarter degree resolution are then used to calculate weekly values of Ekman transport which are combined with the SST fields, also at a quarter degree, to give weekly estimates of the advective heat flux due to Ekman transport. This assumes that horizontal gradients of SST are equivalent to gradients of the sub-surface water being carried by the Ekman transport. We also obtain weekly estimates of the Ekman pumping velocity.

Averaging all the weekly heat flux fields over the four year period from January 2001 to December 2004 leads to the result in Figure 8. The annually averaged Ekman transport is directed to the southwest over the entire domain. The transport is convergent over our mooring, both due to a curvature in the wind field as well as a decrease in magnitude. Also, the advective heat flux due to the Ekman transport, $U_{E} \cdot \nabla T_{S S T}$, is small and positive at our mooring $\left(+6 \mathrm{~W} / \mathrm{m}^{2}\right)$. This is somewhat surprising to us as we had initially assumed that there would be a strong cooling effect due to the advection of upwelled water from the coast past our mooring. Although this is true within $3^{\circ}$ of the coast, note the dark blue contours to the north where the flux is $<-30 \mathrm{~W} / \mathrm{m}^{2}$, it is not true at our location. We can see why this is so by examining the annual mean SST field (recall that the calculations were done weekly, but the region has little temporal variability so that the broad explanation is apparent in the annual means). We see that at our offshore location the Ekman transport is largely parallel to the mean SST isotherms (thick contours in Fig. 8), so that the advective flux is minimal.

We can also see that the spatial pattern of heat advection by the Ekman transport is quite variable. To the northwest of the mooring the flux can be large and positive $\left(>+20 \mathrm{~W} / \mathrm{m}^{2}\right)$ as the winds blow warm surface waters poleward. The coastal region experiences strong cooling as the upwelled water is pushed offshore directly across SST gradients. There is also a region near the coast where the Ekman transport does not provide strong cooling (near 20S, 72W). This is in fact a coastal region with annual net downwelling (in the 


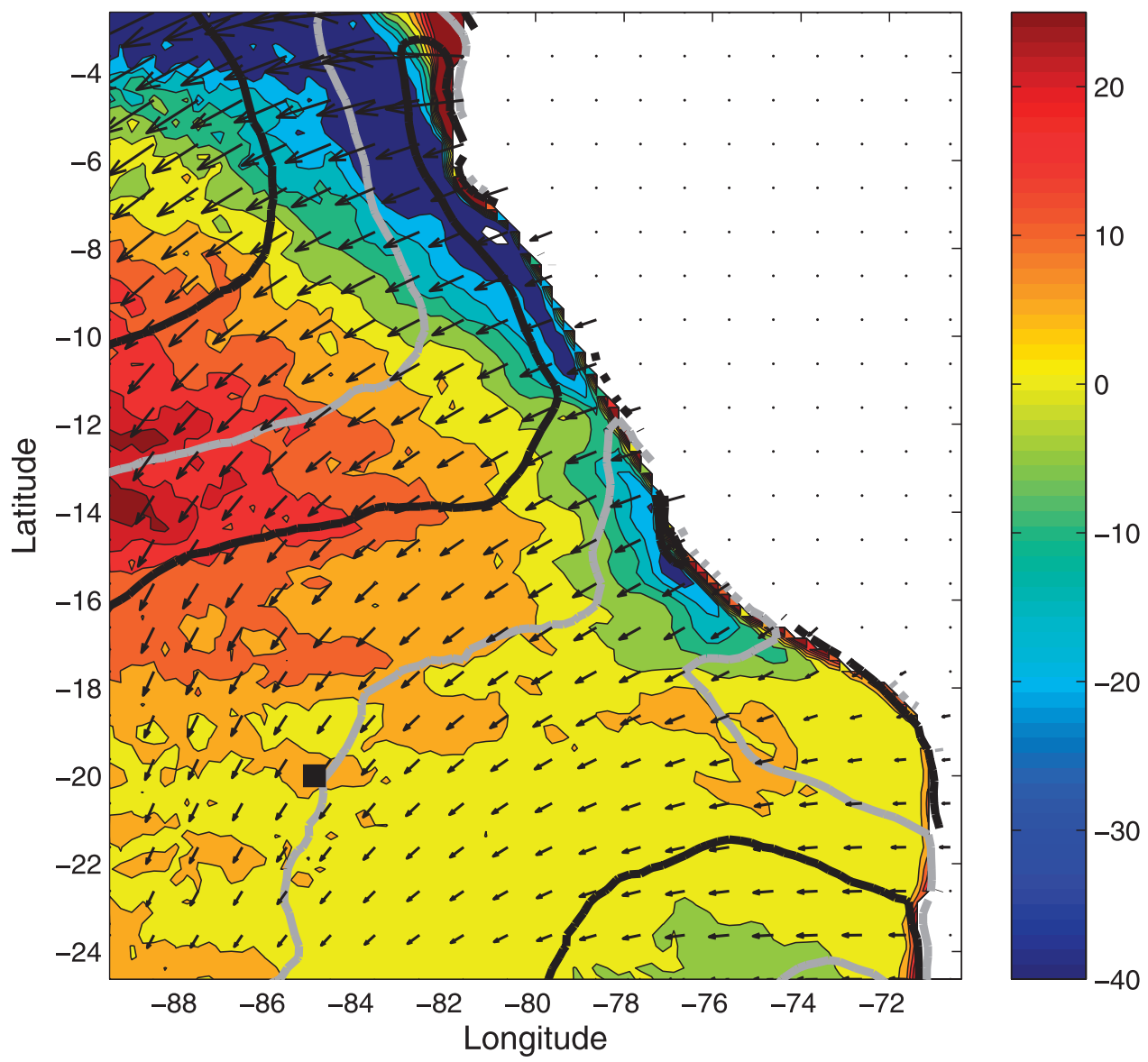

Figure 8. The advective heat flux due to the Ekman transport (filled contours, and associated color bar (in $\left.\mathrm{W} / \mathrm{m}^{2}\right)$ ), SST contours (alternating gray-black thick contours), and Ekman transport (arrows). All fields are averages over the period of January 2001 to December 2004. The SST contours are unlabelled, but progress in 1 degree increments from warm water in the northwest to cool water in the southeast. The mooring location is indicated by the black square.

closest resolvable satellite grid points). The strong convergent curvature of the wind field, forced by the topography of the coastline and the Andes, limits the effect of increasing transport further offshore. Although not shown in the current figure, the coast of Chile further south has a similar pattern of upwelling as seen along the coast of Peru.

\section{c. Geostrophic advection}

Calculating the transport of heat by the non-Ekman, primarily geostrophic, mean flow is more difficult since we know very little about the horizontal temperature structure below the base of the mixed layer. To do this calculation properly one needs to know $d T / d x$ and $d T / d y$, at the mooring site, as functions of time and depth. One also needs to know the 


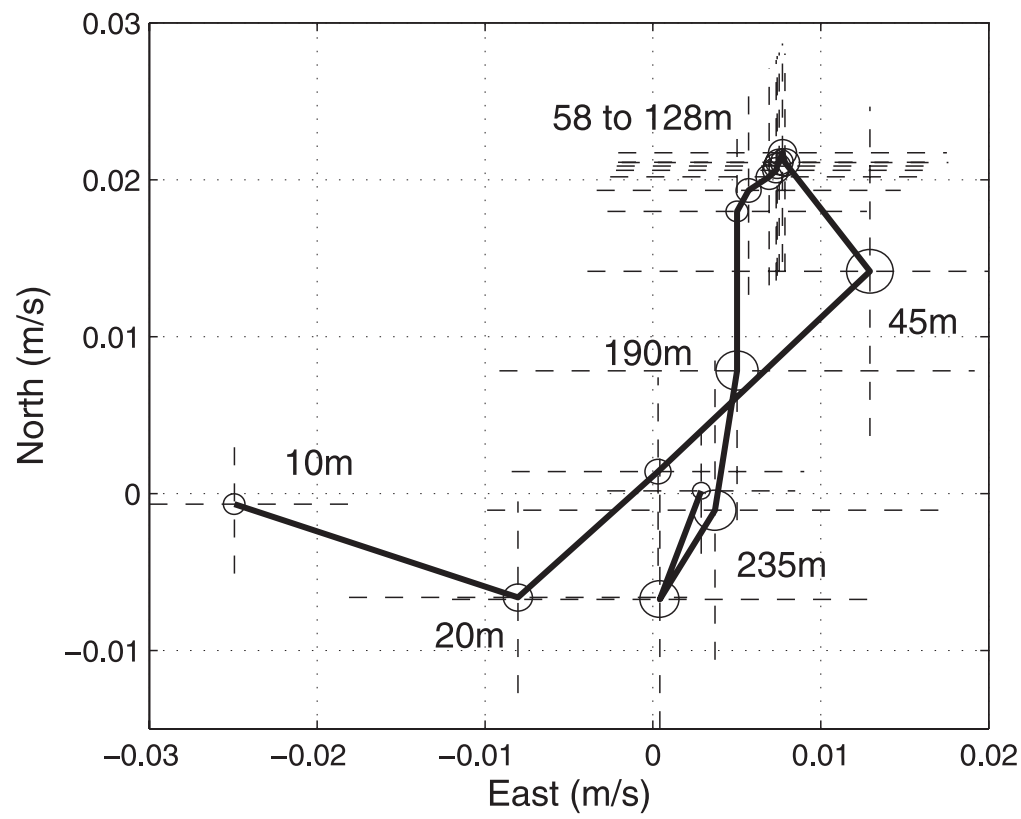

Figure 9. Mean velocity as a function of depth at the Stratus mooring site. Depths are labeled except for observations at 32.5, 290 and $350 \mathrm{~m}$. The ellipses represent the observational $95 \%$ confidence limits. The crosses are $95 \%$ confidence limits on the climatological significance of the velocities. The degrees of freedom have thus been scaled by a decorrelation timescale of approximately 15 days.

geostrophic velocity, $u_{g}$, but for this one can substitute the velocity records for depths below the Ekman layer. The progressive vector plot (Fig. 5) leads us to believe that there is little shear in the geostrophic flow above the thermocline. This is only a qualitative statement as we cannot properly resolve the Ekman layer. Figure 9 shows the mean velocities at each depth for the four years of observations. We can see that there is only weak shear in the ADCP bins between $128 \mathrm{~m}$ and $58 \mathrm{~m}$. The exact nature of the flow below the thermocline is not well resolved since we have had only one year of observations at 190 and $290 \mathrm{~m}$, and 2 years at $235 \mathrm{~m}$. The flow at $350 \mathrm{~m}$ is a four year average. Still we can see that the flow is moving more slowly, and during Stratus 4 was actually flowing poleward at all depths below $190 \mathrm{~m}$. In practice, the temperature gradient below the thermocline is weak $(<0.1 \mathrm{~K}$ per $100 \mathrm{~km})$ and so will contribute little advective heat flux regardless of the choice of current. For the geostrophic advection calculation we shall use the observed mean currents at all depths below $58 \mathrm{~m}$. Above this depth we use the value at $58 \mathrm{~m}$.

For the temperature gradient we must rely on the World Ocean Atlas (WOA) historical climatology (Fig. 10). This begs the question of why we don't use thermal wind to be self-consistent. However, the climatology has a true resolution of 1 degree of latitude by 10 degrees of longitude (in the Southeast Pacific). Clearly the longitude resolution is too coarse to estimate meridional velocity, which is dominant over the zonal component at this 

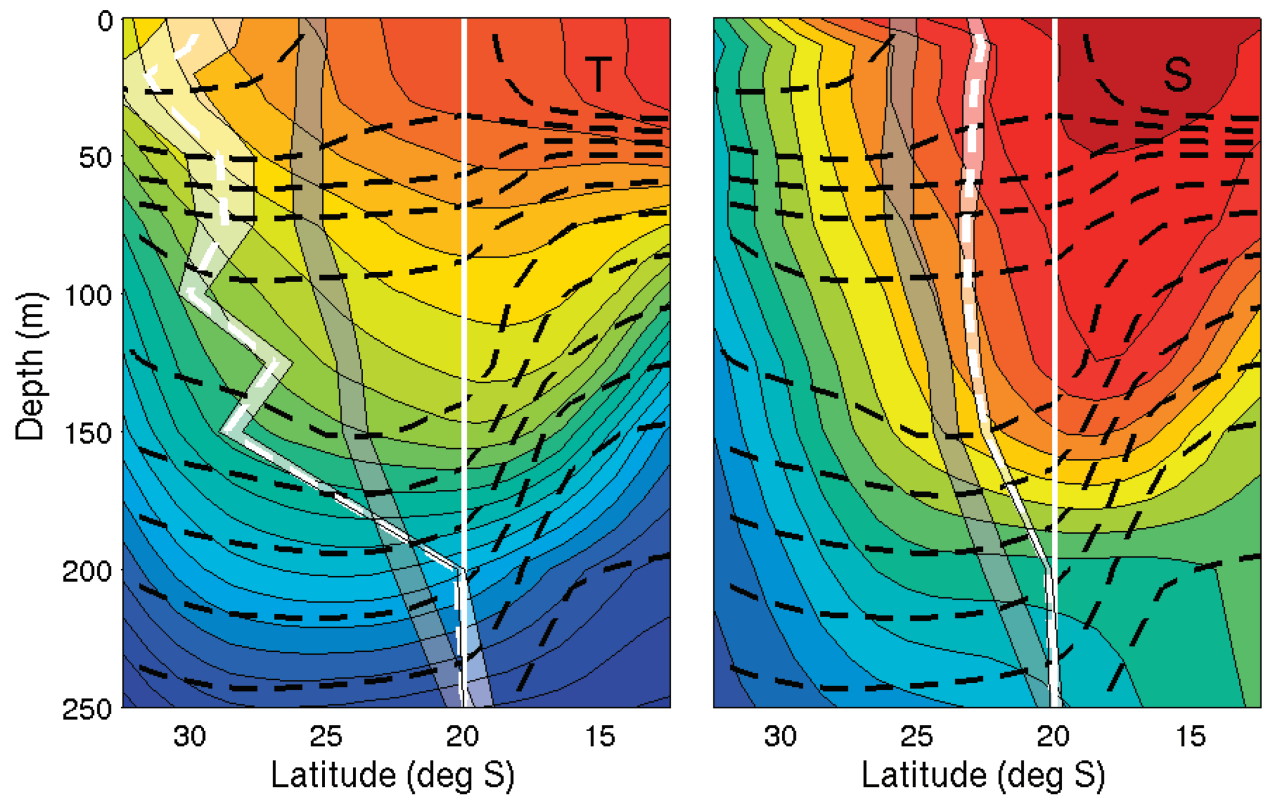

Figure 10. Annual average temperature (left: $0.5^{\circ} \mathrm{C}$ spacing) and salinity (right: 0.1 psu spacing) contours from the World Ocean Atlas along a transect at $85^{\circ} \mathrm{W}$. Dashed contours represent neutral density surfaces (spaced every $0.2 \mathrm{~kg} / \mathrm{m}^{3}$ ). The vertical white line is the location of the mooring. The grey shaded region is the location of the water parcels one year "upstream" from the mooring. Also plotted is the vertical profile representing the gradient between the mooring and the grey band calculated along neutral density surfaces (white dashed plus shaded $90 \%$ confidence limits). The vertical white line at the mooring serves dual purpose as the y-axis for this presentation, and the plots are scaled so that 1 degree of latitude equals $0.1 \mathrm{~K}$ and 0.1 psu respectively.

location. This also implies that the only resolvable gradient is $d T / d y$. In addition, this is a region of limited data, which makes us skeptical of the 1 degree resolution in the meridional direction. We shall therefore estimate the temperature gradient over a larger spatial scale, hoping that this eliminates any white noise in the climatology. This has to be balanced against too large a scale where curvature effects become important.

Thus we approximate the geostrophic portion of the advective term in the heat content equation by,

$$
\int_{0}^{1 \text { year }} \int_{z 0}^{0} u_{g} \cdot \nabla T d t d z=-\int_{z 0}^{0} T\left(x_{0}, y_{0}, z\right)-T\left(x_{0}-\int u_{g} d t, y_{0}-\int v_{g} d t, z\right) d z
$$

where $T\left(x_{0}, y_{0}, z\right)$ is the temperature profile at the mooring, and $T\left(x_{0^{-}} \int u d t, y_{0^{-}} \int v d t, z\right)$ is the temperature profile at the point where the water was one year ago. This has the potential problem that the velocity measured at the mooring may not be representative of the surrounding water mass velocities. Namely we are estimating a Lagrangian quantity from an Eulerian measurement. However, we do not feel that there are strong divergences or 
curvatures to the annually averaged quasi-geostrophic flow field on the scales of interest, $O(500 \mathrm{~km})$. One could argue that the flow is actually along neutral density surfaces, not depth surfaces, and so the gradients of temperature should take this into account.

Figure 10 shows the temperature (and salinity) contours from the World Ocean Atlas as well as neutral density surfaces (dashed black lines) along a meridional transect at $85 \mathrm{~W}$. The shaded gray band represents our $90 \%$ confidence interval surrounding the one-year "upstream" location. Here the location is derived from the velocities in Figure 9, but the error has been arbitrarily doubled in an attempt to account for flow curvature. The vertical white line is the mooring position. Superimposed on the figure is the estimate of the difference in temperature (and salinity) between the mooring and the one year "upstream" location (dashed white line). Here the mooring location serves a dual purpose as the y-axis, and the temperature and salinity have been scaled so that one degree of latitude equals $0.1 \mathrm{~K}$ and $0.1 \mathrm{psu}$, respectively. The white shaded band is the $90 \%$ confidence limit assuming the atlas data is perfect and the only errors arise from uncertainties in the velocities. We shall discuss climatology errors in the discussion.

The gyre-scale circulation is clearly important in importing cool, fresh water to the stratus region. The upstream differences along neutral density surfaces are approximately $-1{ }^{\circ} \mathrm{C}$ and -0.3 psu above the thermocline. The importance of the sloping density surfaces is particularly important for temperature, since the gradient along neutral density surfaces is 30\% larger than a constant-depth gradient. The temperature difference in Figure 10 also includes a small component due to the zonal advection. To determine this we had to rely upon shipboard CTD and XBT casts to reconstruct the zonal gradients. This component is highly uncertain but contributed only $10 \%$ of the quasi- geostrophic advective heat flux. Expressed as an equivalent heat flux the geostrophic advection term contributes $-20 \mathrm{~W} / \mathrm{m}^{2}$ (when integrated to $250 \mathrm{~m}$ depth), of which $-16 \mathrm{~W} / \mathrm{m}^{2}$ comes above the thermocline (defined here as $130 \mathrm{~m}$ ).

Assuming that the atlas data is accurate, the only errors enter the equation through the geostrophic velocity. We have been careful in forming the multi-year average to examine the impact of aliasing a large eddy signature into the mean. A second mean velocity was calculated by first removing clear eddy signatures from the record (as determined from thermocline height, sea- surface height anomaly, and velocity anomaly). The mean of this record was remarkably close to the average of the entire record. The heat flux calculated from the "eddy-less" velocity was within $2 \mathrm{~W} / \mathrm{m}^{2}$ of the original calculation. Also the velocity profile was reconstructed from multiple velocity sensors with uncorrelated error properties, so that the vertical integral should have minimal error due to instrument bias. As mentioned before flow curvature over the $500 \mathrm{~km}$ annual mean path is expected to be small at our location. A quick examination of the results from a large computer model (NCAR CCM2) support this argument (Markus Jochum, pers. comm.). We have arbitrarily doubled the standard error of the mean from the velocity calculation to account for this mild curvature. Integrating from the surface to $250 \mathrm{~m}$ gives a $90 \%$ confidence limit of $\pm 6^{\circ} \mathrm{Cm}$ or about $\pm 1 \mathrm{~W} / \mathrm{m}^{2}$. A similar error bar exists for the integral from the surface to 
the thermocline $(130 \mathrm{~m})$. However, the uncertainties in the WOA field are likely to be the biggest source of error.

\section{d. Ekman pumping flux}

The Ekman pumping velocity term is difficult to estimate since we do not know the vertical profile of the Ekman pumping velocity, $w_{E}(z)$. However, we can make a plausible guess for its structure by assuming Sverdrup dynamics dominate. We shall use the mooring data to form seasonal averages of meridional velocity, $v(z)$. With four years of data the effect of the eddy field on the mean can be greatly reduced. We can then apply the Sverdrup relation $d w_{E} / d z=\beta v / f$ to obtain seasonal profiles of the gradient of the Ekman pumping velocity. These profiles can be vertically integrated, and the near-surface maximum matched to the predicted Ekman pumping velocity derived from QuikScat wind curvature on 0.5 degree scales. This matching is necessary since we do not have enough instrumentation in the upper $20 \mathrm{~m}$ to properly measure the Ekman layer itself.

The resulting Ekman pumping induced displacement is show in Figure 11. Examining the annual signal first, we note that the displacement reaches a maximum $(-26 \mathrm{~m} / \mathrm{year})$ at about $30 \mathrm{~m}$ depth. Below this level the equatorward mean flow tends to reduce the downwelling until the displacement is zero near the thermocline (at $150 \mathrm{~m}$ ). Below this depth the interpretation is more difficult since the velocities are based upon shorter averages, and could therefore represent a single anomalous year. Furthermore, they are no longer truly related to Ekman pumping but are presumably a result of exchange between the ventilated thermocline and the underlying waters. This is consistent with the "internal" thermocline of Samelson and Vallis (1997), which is primarily in advective-diffusive balance. Using their scaling arguments (Eq. 4.4 to 4.6 and 4.15 in Samelson and Vallis (1997)), leads to a predicted advective-diffusive vertical scale $(\delta=70 \mathrm{~m})$, "internal boundary layer" scale $\left(\delta_{i}=50-60 \mathrm{~m}\right)$, annual vertical displacement $\left(\eta_{\mathrm{D}}=14 \mathrm{~m}\right)$, and horizontal velocity $(U=0.015 \mathrm{~m} / \mathrm{s})$ that are similar to the observations. In the above we have chosen $\kappa=3 \times 10^{-5} \mathrm{~m}^{2} / \mathrm{s}$, and retained their use of $\Delta T_{D}=10 \mathrm{~K}$. All other variables are obtained from the observations. Alternatively, the quasi-geostrophic flow in this depth range could be convergent.

Examining the seasonal signal we notice that the Ekman pumping is downward at the thermocline during MAM and JJA, with upwelling during SON and DJF. This is remarkably consistent with the climatological temperature (Fig. 3), which shows steady depression of the thermocline from March through October followed by a more sudden rebound. The magnitudes are also similar with the September depth of the $16^{\circ} \mathrm{C}$ isotherm being $14 \mathrm{~m}$ below the March depth, as compared to the Ekman pumping derived value of $10.5 \mathrm{~m}$. We do not necessarily suggest causality, but the correspondence is striking.

The right-hand side of Figure 11 shows the implied heat content change integrated from the surface to depth. Thus the signal increases as long as the Ekman pumping velocity is downwards, but is reduced below the thermocline due to the competing upwelling of cold water. At the thermocline it reaches a maximum of $+6 \mathrm{~W} / \mathrm{m}^{2}$, but is reduced to only + $2.5 \mathrm{~W} / \mathrm{m}^{2}$ at $250 \mathrm{~m}$ depth. 

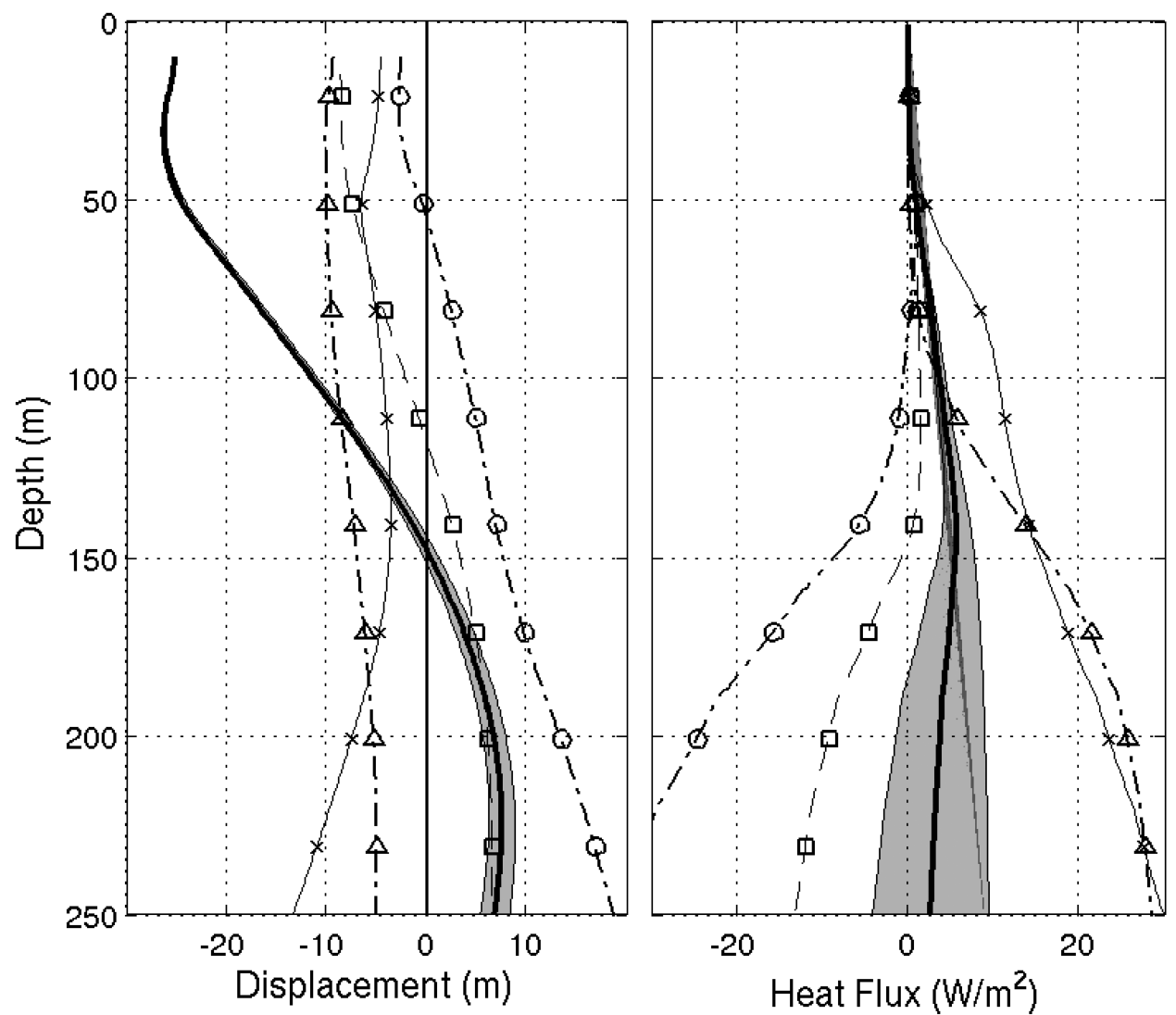

Figure 11. The vertical displacement (left) due to Ekman pumping for each of the four seasons (DJF, circles; MAM, crosses; JJA, triangles; SON, squares) and for the annual mean (thick black line with shaded $90 \%$ confidence intervals). Also, the implied heat flux (right) integrated from the surface to depth $z$.

The vertical temperature gradient is well resolved by our array of sensors. The largest source of error is in the Ekman pumping velocity. There are three contributors to this error. The first is in the applicability of the Sverdrup relation. Because we are in the deep ocean away from any strong frontal dynamics or topography, we argue that Sverdrup relation is very valid near our mooring. The second error source involves the uncertainty in the meridional velocity field. Although one could question the relevance of our four-year average to the true climatological mean flow, we measure the four-year average flow to better than $0.0002 \mathrm{~m} / \mathrm{s}$. Again these errors are uncorrelated with depth, due to our use of multiple instruments, and so the vertical integration reduces the fractional error even more. The third and potentially largest error is in the satellite derived Ekman pumping used for the near surface matching condition. We believe that the Ekman pumping is dominated by the large-scale Trade wind jet which is well resolved by QuikScat. Satellite winds may not resolve small-scale features, but we are not aware of any reason why small features would 
have a preferred curvature in the deep ocean (at least in the subtropical gyre). The fact that the implied displacement passes through zero near the thermocline is very reassuring. However we could add $\pm 5 \mathrm{~m}$ to Ekman pumping displacement and still obtain a zero crossing in the vicinity of the thermocline. The above uncertainty in total Ekman pumping translates into an error in the heat flux of $\pm 5 \mathrm{~W} / \mathrm{m}^{2}$ when integrated to $250 \mathrm{~m}$ depth, and half that at the thermocline.

\section{e. Vertical diffusion}

The role of vertical diffusion in the heat content analysis is restricted by our choice of integration depth. At $250 \mathrm{~m}$ the vertical gradient is small $(0.025 \mathrm{~K} / \mathrm{m}$, see Fig. 2), and so assuming a moderately large vertical diffusivity $\left(\kappa_{\mathrm{v}}\right)$ of $3 \times 10^{-5} \mathrm{~m}^{2} / \mathrm{s}$ leads to a heat flux of $-3 \mathrm{~W} / \mathrm{m}^{2}$. However, diffusivity does play an important role in redistributing heat within the box. In particular at the thermocline the gradient can be seven times larger leading to a flux of $20 \mathrm{~W} / \mathrm{m}^{2}$ (whose sign depends upon which box we are considering).

\section{f. Closing the heat budget}

We have now evaluated all the terms except for the problematic eddy flux divergence, and so can calculate this term as a residual. We will later return to observational constraints on the eddy flux divergence. Adding together the known terms and their error estimates gives,

$$
(44 \pm 5)+(6 \pm 4)+(-20 \pm 5)+(2.5 \pm 5)+(?)+(-3 \pm 2)=(0 \pm 6),
$$

where the terms on the left-hand side are the surface heat flux, Ekman advection, quasi-geostrophic advection, Ekman pumping/ vertical advection, unknown eddy fluxes, and diffusion, respectively, and the left-hand side is the observed temperature trend. Thus the eddy flux divergence should equal $-30 \pm 12 \mathrm{~W} / \mathrm{m}^{2}$. This is a large source of cooling and it is bounded away from zero. The mesoscale eddy field as a source of strong cooling is plausible. Satellite observations show that coherent mesoscale eddies are produced near the coast (Chaigneau and Pizarro, 2005). These then propagate westward, slowly spinning down and dissipating as they age. Thus eddies could represent an advective transport of water from the upwelling region to the deep ocean. They also would induce local stirring across meridional temperature gradients.

Some may question our choice of lower bound and so we can perform the above calculation from the surface to $130 \mathrm{~m}$ depth (roughly the average top of the thermocline). The values of the terms are then given by,

$$
(44 \pm 5)+(6 \pm 4)+(-16 \pm 5)+(6 \pm 2.5)+(?)+(-20 \pm 5)=(0 \pm 4) .
$$

We again see a role for eddy flux divergence $\left(-20 \pm 11 \mathrm{~W} / \mathrm{m}^{2}\right)$, although somewhat reduced.

The subthermocline layer $(130-250 \mathrm{~m})$ is primarily in advective-diffusive balance with net vertical diffusive heating $\left(+17 \mathrm{~W} / \mathrm{m}^{2}\right)$, being balance by horizontal $\left(-4 \mathrm{~W} / \mathrm{m}^{2}\right)$ and vertical $\left(-3.5 \mathrm{~W} / \mathrm{m}^{2}\right)$ advection and eddy flux divergence $\left(-9.5 \mathrm{~W} / \mathrm{m}^{2}\right)$. We are encouraged 
by the fact that the eddy flux divergence term is split relatively equally between the upper and lower box, as this is consistent with our idea of mesoscale eddies leaking fluid from their core.

\section{g. Eddy flux divergence}

The above arguments lead us to believe that there should be a significant cool and fresh flux of water due to the eddy field. Can we find any evidence in the observations to support this idea? To begin with let us examine the eddy flux at our mooring site. We can then consider certain scaling arguments to get an idea of the potential magnitude of this term.

As with all eddy flux estimates we need to first consider what is the mean. In this case we have used the seasonally averaged velocity in the geostrophic flow and Ekman pumping calculations, so we shall high pass our observations at a 3-month half power point to obtain the fluctuations. The result of this simplistic calculation for three depths is shown in Figure 12.

We see that there are significant features that show up in the eddy heat flux, and that they are generally well correlated with depth. In particular the single large event between days 150 and 200 of 2001 is very indicative of the passage of a geostrophic eddy, as is the event near day 340 of year 2000. Referring back to the earlier temperature plot, Figure 4, we see that both these time periods correspond to dramatic upward shifts in the location of the thermocline. It would thus seem likely that these are cold core eddies that have been advected offshore from the upwelling region. The fact that the signal is similar in the near-surface temperature and velocity fields lends strength to this hypothesis.

Now if these eddies that have been transported offshore were to slow down and eventually dissipate, than that would represent a significant input of cold water to these offshore regions. As a first guess let us assume that the eddy fluxes observed at our mooring $O\left(0.1^{\circ} \mathrm{Cm} / \mathrm{s}\right)$ were to go linearly to zero over a distance of $1000 \mathrm{~km}$ (a purely arbitrary number). In this hypothetical case, the eddy flux divergence term would result in a net cooling of the entire water column above the thermocline by $3^{\circ} \mathrm{C}$ in one year. There are numerous problems with this calculation, but it does indicate that the eddy flux of heat is significant and that the divergence of the eddy flux could be an important part of the local heat budget.

The fact that the eddy correlations of heat and temperature have variability at $10 \mathrm{~m}$ depth leads us to speculate about the possibility of deriving the eddy flux divergence from satellites (i.e. using sea-surface height and sea-surface temperature fields). However, a more careful look at Figure 4 shows that many of the distinct cooling events at the thermocline have no surface signature. This is consistent with the idea that a cold, upwelled eddy will quickly form a surface cap due to surface warming. We note that eddies that pass by our mooring are about a year old (based on a predicted westward translation of $7 \mathrm{~cm} / \mathrm{s}$ ).

The coastally generated eddies do have observable signatures in the sea-surface height (SSH) field. Chaigneau and Pizarro (2005) performed an analysis of the sea-surface height field using the multi-satellite merged product provided by AVISO (as well as analyzing surface drifter tracks). They noted a predominance of anticyclonic energy in the drifter 


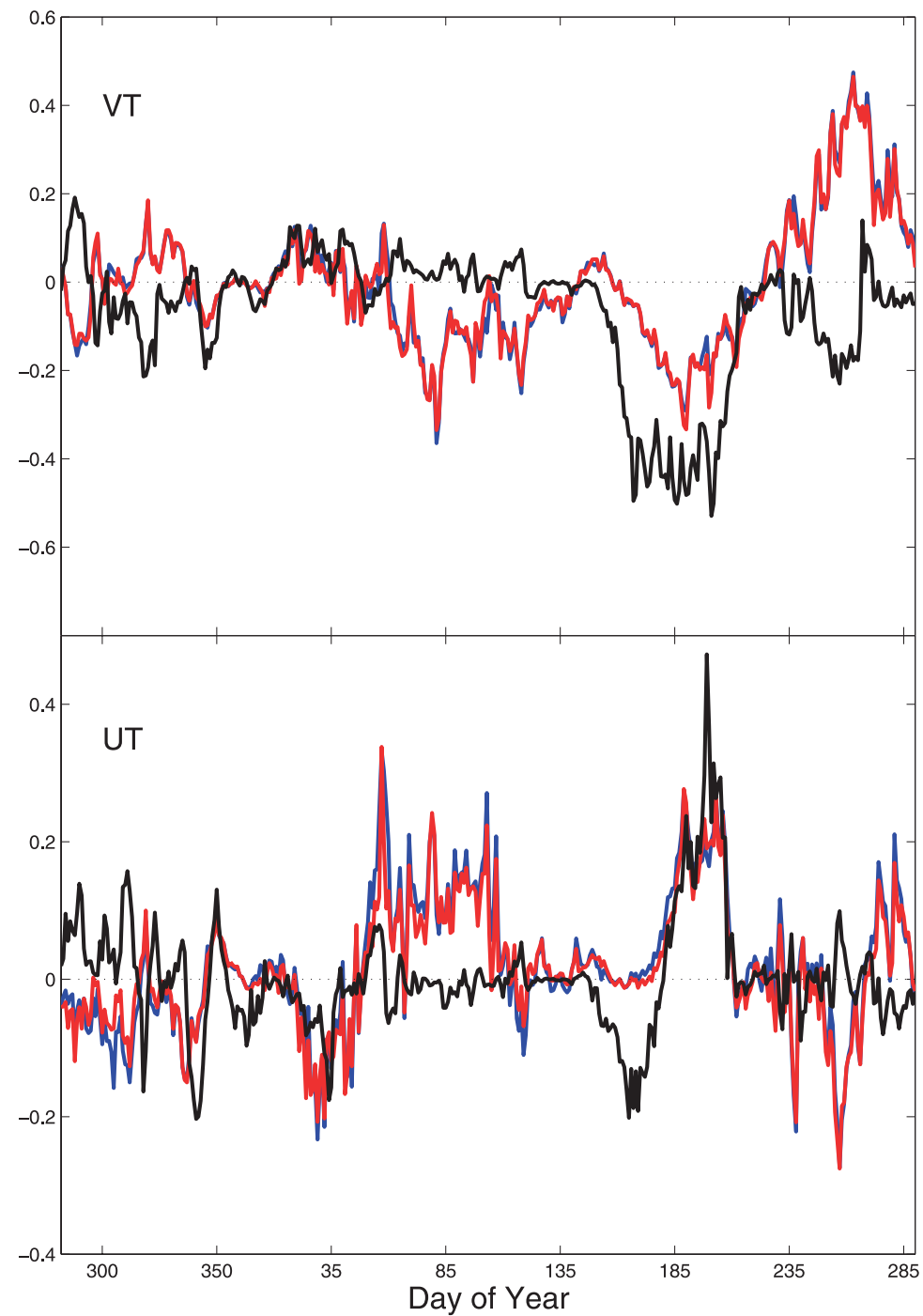

Figure 12. Estimates of the two components of the eddy flux of heat, during the first year of deployment, at three different depths: 10 meters (blue), 20 meters (red) and 130 meters (black).

tracks, and that anticyclonic eddies were longer lived and more common than cyclonic eddies in the SSH anomaly fields. A selection of drifter tracks from the region shows the looping behaviour associated with eddies (Fig. 13). They showed that anticyclonic rotation was twice as common as cyclonic rotation in the drifter tracks. We believe that in the region of our mooring that the asymmetry is even larger. Their domain extended to $35 \mathrm{~S}$ and so included part of the subtropical front, which was heavily weighted by the available drifter tracks. This frontal region is more likely to have an equal partition of rotational eddies. Eddies formed from coastal upwelled water, which travel past our mooring, must 


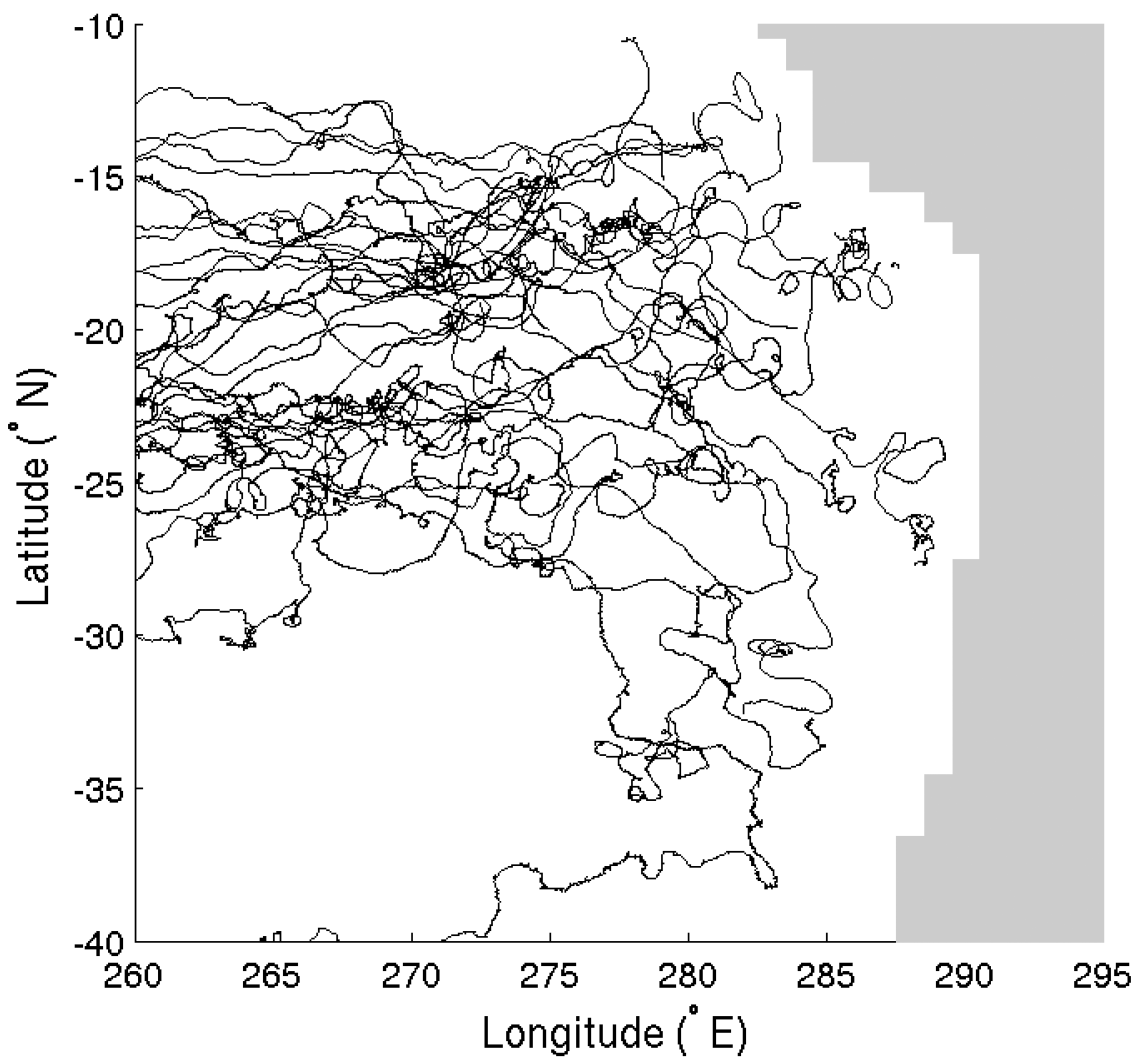

Figure 13. A selection of some of the drifter tracks used in the diffusivity calculations.

be anticyclonic to satisfy geostrophy. There is no regional source of locally warm water with which to form cyclones. Also there SSH analysis just looked at anomaly heights instead of using an Okubo-Weiss scheme (Isern-Fontanet et al., 2004). If the regional oceanography consists of the large-scale wind-driven flow plus anticyclonic eddies than the SSH average is biased away from the wind-driven background flow because of the lack of cyclones.

It should be noted that these eddies are not strictly diffusive. Thus a parameterization based upon eddy kinetic energy arguments (e.g. Stammer, 1997) will not be adequate. In a similar vein, Zhurbas and Oh $(2003,2004)$ analyzed drifter tracks to obtain decorrelation times, and hence diffusivities. We repeat their global calculation locally for all drifters within a 10 degree of latitude by 15 degree of longitude box centered on the mooring. The ensemble average integral time scales are 4 and 3.5 days for the East and North velocity components respectively. The first zero crossings are 4-5 times larger than the integral time scales because the covariances are quite steeply peaked near zero. Multiplying by the velocity variance gives ensemble averaged diffusivities of $2700 \pm 200 \mathrm{~m}^{2} / \mathrm{s}$ and $2100 \pm$ $150 \mathrm{~m}^{2} / \mathrm{s}$ for the east and north components, respectively. It would be wrong to use this 
diffusivity to characterize the eddy's mixing. To start with these are long-lived coherent eddies not small-scale turbulent eddies. Thus the velocity variance is not all available for lateral mixing. Hence the diffusivity calculated in this way is an upper bound on the real stirring effect of the eddies. Secondly, the near-surface drifters are invariable removed from the eddies by the Ekman transport and so will have relatively shorter decorrelation times than a drogued float at thermocline depth. If we persist in this calculation by applying the above diffusivity to the WOA temperature and salinity fields we find that the implied diffusivity over our $250 \mathrm{~m}$ deep domain is only $10 \pm 5 \mathrm{~W} / \mathrm{m}^{2}$ (an overestimate). Thus the majority of the eddy contribution is through the exchange of the eddy core water with the background, not the eddy stirring the background.

\section{h. A quick look at salt}

The above process can be carried out for salt with some minor changes. We do not yet have operational sea-surface salinity from satellites. Thus for the Ekman advection we need to use WOA data, and will consequently loose the temporal resolution available from satellites. However, if one estimates the Ekman advection of temperature not from an average of weekly calculations but by a calculation on the annual mean one ends up with similar results. Thus the Ekman advection of heat, and presumably salt, is dominated by the largest time scales. This is a largely independent calculation, although with bigger error bars due to a smaller number of observational constraints.

The left-hand side of the equation will be estimated from the available observations in two ways. One is to integrate the existing salinity measurements in time. The other is to use the coexisting salinity and temperature measurements to create seasonal T-S relationships, and then extrapolate from the higher density temperature observations. In either case there is no trend that is significantly greater than zero at a $50 \%$ confidence interval. And the four years of variability are constrained within a pessimistic bound of $\pm 12 \mathrm{psu}$ m.

The equation for salt, integrated from the surface to $250 \mathrm{~m}$, yields values of

$$
(40 \pm 4)+(6 \pm 5)+(-52 \pm 3)+(16 \pm 5)+(?)+(1 \pm 1)=(0 \pm 12) .
$$

This implies an eddy flux divergence of $-11 \pm 15 \mathrm{psu}$ m. In keeping with our conceptual idea, the eddy flux divergence term provides freshening. Since the coastal upwelled water is both cold and fresh, relative to the offshore, this is reassuring. Due to the large uncertainties in the salt budget we will restrain from any deeper analysis.

\section{Discussion}

Although we are confident in the general conclusion that eddies play an important role in the offshore heat and salt budgets, we need to consider some alternative explanations. To start, we shall consider some of the likeliest sources of error in our calculation.

The biggest potential issue with the radiation measurements is the absolute accuracy of the longwave sensor. Although we can get a mean difference between the two redundant sensors of better than $\pm 5 \mathrm{~W} / \mathrm{m}^{2}$ on daily or longer averages, there is a question about 
whether there is a mean bias in both sensors. Our sensors are all calibrated before deployment and checked after recovery in a blackbody chamber (Payne and Anderson, 1999). The calibrated sensors are then compared against each other and additional sensors here at WHOI before deployment. The sensors are also compared during the deployment and recovery cruises with additional ship-board longwave measurements. Despite all these procedures it is very difficult to assign an absolute accuracy to the longwave sensors. However, we feel that the absolute accuracy is at worst $\pm 5 \mathrm{~W} / \mathrm{m}^{2}$, and is probably only $\pm 3 \mathrm{~W} / \mathrm{m}^{2}$. There is also little reason to assume that this absolute error would be consistently positive or negative.

Another error source could be due to the pitch and roll of the buoy (MacWhorter and Weller, 1991). This would decrease the measured solar radiation since the instrument would see part of the ocean instead of the sky. If this were an issue, then correcting for it would increase the surface heat flux which is the opposite of what we are attempting. The measured longwave would probably be mildly increased, since the sea-surface temperature is about $7^{\circ} \mathrm{C}$ warmer than the stratus clouds. Thus making this correction would reduce the net surface heat flux. However, we cannot correct the longwave without also correcting the shortwave, and since the shortwave flux is larger this would worsen, not improve, the estimated heat budget. The sensible heat flux is negligible so we will ignore that term. The biggest issue with the latent heat flux might be that it is derived from a bulk formula rather than directly measured. Increasing the latent heat flux by $-15 \mathrm{~W} / \mathrm{m}^{2}$ would improve the closure of the heat budget, but would also add an extra $18 \mathrm{~cm}$ a year of evaporation. This would add about 6 psu $\mathrm{m}$ to the salt budget. However, there is little reason to believe that the bulk formula are inaccurate too such a large degree. In particular, detailed comparisons of the buoy data with shipboard direct covariance measurements during the recovery and deployment cruises shows that latent heat flux estimates are within 5\% (on those specific times). Also the prevailing conditions at the buoy consist of moderate winds $(6-8 \mathrm{~m} / \mathrm{s})$ and an unstable boundary layer. This is a region of meteorological phase space where the bulk formulas work well.

The Ekman advection of heat is negligible near our mooring and we can think of no method to introduce a cool bias. The geostrophic advection term is admittedly crude, but we would need to double it in order to substantially change the heat equation. Although the accuracy of the WOA temperature profiles in our data sparse region is suspect, I doubt that the mean temperature gradient is off by a factor of 2 . There could instead be a permanent small-scale feature near our mooring such that the local temperature gradient is 2 times larger than the large-scale estimate. But there is no evidence for such a feature, nor would we be able to explain its cause and persistence. It thus seems unlikely that we could achieve more than an extra $-5 \mathrm{~W} / \mathrm{m}^{2}$ from geostrophic advection. However, this would add -15 psu $\mathrm{m}$ to the salt budget, an unsupportable change. Changing geostrophic advection would not help close the budgets.

The Ekman pumping heat flux is small, and due to the convergence of water at our mooring must be a source of heating. Eliminating it entirely would not change the overall result. Finally the vertical diffusion term, even invoking double diffusive processes, can at 
best double in magnitude. One additional process that could affect the heat budget is the divergence of the geostrophic flow, particularly if this flow was divergent above the thermocline and convergent below for this would force a compensating upwelling across the thermocline. However, this potential situation is captured in our Sverdrup calculation and so we cannot add it twice. The drizzle rate is another possible source of error, but it is such a small term that even being wrong by a factor of two would not significantly change the salt budget.

We are thus left with the conclusion that the leakage of cold, fresh water from the upwelling eddies is an important part of the heat budget in the southeast subtropical Pacific. To investigate this a little further, let us consider a simple calculation. Consider a $20 \times$ 20 degree box into which a cold eddy propagates, stalls and eventually spreads and mixes. If the eddy had a radius of $120 \mathrm{~km}$ and the background water was $2^{\circ} \mathrm{C}$ warmer than the eddy water then the cooling represented by mixing the eddy with the background water is equivalent to $-1 \mathrm{~W} / \mathrm{m}^{2}$ (when integrated to $250 \mathrm{~m}$ depth). Thus our postulated eddy flux divergence is equivalent to forming one eddy per degree of coastline each year.

\section{Conclusions}

The ocean under the stratus deck is governed by the interplay of local and external forcings. Surface fluxes contribute substantial inputs of heat and salt to the water column $\left(\approx 45 \mathrm{~W} / \mathrm{m}^{2}\right.$ and $40 \mathrm{psu} \mathrm{m}$, respectively). These must be balanced by inputs of cool, fresh water on annual (or at most inter-annual) time scales. The large-scale gyre circulation transports water equatorward, although it only balances half of the heat, and two thirds of the salt, input. Vertical diffusion could be important across the thermocline, but we have taken our depth of integration well below the thermocline in order to make this term minimally important. The Ekman transport of water offshore is not important for the heat and salt budgets, because the water has largely come into equilibrium with its surroundings by this point and travels along surface gradients of temperature and salinity. Ekman pumping provides an additional source of heat and salt, but is small since the vertical Ekman velocity is close to zero by the depth of the thermocline.

The only remaining term is the eddy flux divergence of heat and salt. This has to be an important term, even if we are unable to provide good observational bounds on its magnitude. The fact that this term is important also helps to indicate why models have a hard time reproducing the climate of this region. Eddies are notoriously difficult to account for in models where they are not explicitly resolved. Our results would tend to indicate that an ocean-only model would also have a difficult time maintaining the correct upper ocean structure in this region, if forced with the correct surface fluxes.

Constraining the eddy flux divergence with observations is a daunting challenge since the features are large-scale and probably intermittent in nature. Instrumenting sufficient moorings and obtaining sufficient ship time to carry out such a project is unrealistic. Some form of subsurface spatially varying observations would be of great benefit. A set of drifters drogued at a depth near the thermocline which measure temperature would give 
useful data. Also a subsurface glider could help to significantly reduce the uncertainty in temperature and salinity gradients below the mixed layer.

With the existing data it appears that mesoscale features (presumably eddies) are crucial to understanding the cool ocean temperatures of the region. However, they are not the only issue with the observations. Simply increasing the number of eddies to balance the heat budget would unduly freshen the salt budget.

Eddies are probably the physics which is missing from the models. Although, the horizontal eddy diffusivity in the model could be tuned to provide a better fit, this does not address the longer term issues related to modeling future states of the ocean. It seems clear that a better understanding of the forcing mechanism for the eddies, presumably related to the Peru-Chile current system, needs to be obtained so as to be able to correctly account for potential changes in the number, size and water properties of these eddies. It is also unclear that an eddy diffusivity parameterization is appropriate when dealing with only a few, intermittent eddies. A high resolution modeling study of these issues would certainly be worthwhile.

Acknowledgments. Jason Smith, Paul Bouchard and Jeff Lord have provided invaluable technical support to the observational program. The shipboard direct flux measurements carried out by the NOAA Environmental Technology Laboratory have been invaluable in clarifying subtle changes in the buoy meteorological sensors. We thank Jeff Nystuen of the University of Washington Applied Physics Laboratory for data from acoustic sub-surface rain gauges deployed on the Stratus moorings. Support for the buoy deployments and the analysis from NOAA is greatly appreciated (Grants NA17RJ1223 and NA17RJ1224).

\section{REFERENCES}

Bakun, A. and C. S. Nelson. 1991. The seasonal cycle of wind-stress curl in subtropical eastern boundary current regions. J. Phys. Oceanogr., 21, 1815-1834.

Barnett, T. P. 1977. The principal time and space scales of the Pacific Trade Wind fields. J. Atmos. Sci., 34, 221-236.

Bigg, G. R. and A. E. Gill. 1986. The annual cycle of sea level in the eastern tropical Pacific. J. Phys. Oceanogr., 16, 1055-1061.

Boville, B. A. and P. R. Gent. 1998. The NCAR climate system model, version one. J. Climate, 11, $\underline{1115-1130 .}$

Chaigneau, A. and O. Pizarro. 2005. Eddy characteristics in the eastern South Pacific. J. Geophys. Res., 110, doi:10.1029/2004JC002815.

Chelton, D. B. and M. G. Schlax. 1996. Global observations of oceanic Rossby waves. Science, 272 , 234-238.

Colbo, K. and R. Weller. 2007. The accuracy of the IMET sensor package. J. Atmos. Oceanic Technol. (submitted).

Comstock, K. K., C. S. Bretherton and S. E. Yuter. 2005. Mesoscale variability and drizzle in southeast Pacific stratocumulus. J. Atmos. Sci., 62, 3792-3807.

Davis, R. E. 1998. Preliminary results from directly measuring middepth circulation in the tropical and South Pacific. J. Geophys. Res., 103, 24,619-24,639.

Fairall, C. W., E. F. Bradley, D. P. Rogers, J. B. Edson and G. S. Young. 1996. Bulk parameterization of air-sea fluxes for TOGA COARE. J. Geophys. Res., 101, 3747-3764.

Goldenberg, S. B. and J. J. O'Brien. 1981. Time and space variability of tropical Pacific wind stress. Mon. Wea. Rev., 109, 1190-1207.

Grimshaw, R. and J. S. Allen. 1988. Low-frequency baroclinic waves off coastal boundaries. J. Phys. Oceanogr., $18,1124-1143$. 
Hormazabal, S., G. Shaffer, J. Letelier and O. Ulloa. 2001. Local and remote forcing of sea surface temperature in the coastal upwelling system off Chile. J. Geophys. Res., 106, 16657-16671.

Isern-Fontanet, J., J. Font, E. Garcia-Ladona, M. Emelianov, C. Millot, and I. Taupier-Letage. 2004. Spatial structure of anticyclonic eddies in the Algerian Basin (Mediterranean Sea) analyzed using the Okubo-Weiss parameter. Deep-Sea Res. II, 51, 3009-3028.

Johnson, G. C. and M. J. McPhaden. 1999. Interior pycnocline flow from the subtropical to the equatorial Pacific Ocean. J. Phys. Oceanogr., 29, 3073-3089.

Ma, C.-C., C. R. Mechoso, A. Robertson and A. Arakawa. 1966. Peruvian stratus clouds and the tropical Pacific circulation: A coupled ocean-atmosphere GCM study. J. Climate, 9, 1635-1645.

MacWhorter, M. A. and R. A. Weller. 1991. Error in measurements of incoming shortwave radiation made from ships and buoys. J. Atmos. Oceanic Technol., 8, 108-117.

Miller, R. L. 1997. Tropical thermostats and low cloud cover. J. Climate, 10, 409-440.

Payne, R. E. 1972. Albedo of the sea surface. J. Atmos. Sci., 29, 959-970.

Payne, R. E. and S. P. Anderson. 1999. A new look at calibration and use of Eppley precision infrared radiometers. Part II: Calibration and use of the Woods Hole Oceanographic Institution improved meteorology precision infrared radiometer. J. Atmos. Ocean. Tech., 16, 739-751.

Reynolds, R. W., N. A. Rayner, T. M. Smith, D. C. Stokes and W. Wang. 2001. An improved in situ and satellite analysis for climate. J. Climate, 15, 1609-1625.

Samelson. R. M. and G. K. Vallis. 1997. Large-scale circulation with small diapycnal diffusion: The two-thermocline limit. J. Mar. Res., 55, 223-275.

Schudlich, R. R. and J. F. Price. 1998. Observations of seasonal variation in the Ekman layer. J. Phys. Oceanogr., 28, 1187-1204.

Shaffer, G., S. Hormazabal, O. Pizarro and S. Salinas. 1999. Seasonal and interannual variability of currents and temperature off central Chile. J. Geophys. Res., 104, 29,951-29,961.

Stammer, D. 1997. Global characteristics of ocean variability estimated from regional TOPEX/ POSEIDON altimetry measurements. J. Phys. Oceanogr. 27, 1743-1769.

Thomas, A. C., J. L. Blanco, M. E. Carr, P. T. Strub and J. Osses. 2001. Satellite-measured chlorophyll and temperature variability off northern Chile during the 1996-1998 La Niña and El Niño, J. Geophys. Res., 106, 899-915.

Tourre, Y. M. and W. B. White. 1995. ENSO signals in global upper-ocean temperature. J. Phys. Oceanogr., 25, 1317-1332.

Tsuchiya, M. and L. D. Talley. 1998. A Pacific hydrographic section at $88^{\circ} \mathrm{W}$ : Water-property distribution. J. Geophys. Res., 103, 12,899-12,918.

Vega, A., R. Abarca, Y. du Penhoat, B. Dewitte and O. Pizzaro. 2001. Low-frequency variability in the Southeastern Pacific. AVISO Altimetry Newsletter, 8.

Weller, R. A. 1998. A Scientific Plan for EPIC: An Eastern Pacific Investigation of Climate Processes in the Coupled Ocean-Atmosphere System. 90 pp. http://www.pmel.noaa.gov/tao/epic

Weller, R. A. and S. P. Anderson. 1996. Surface meteorology and air-sea fluxes in the western equatorial Pacific warm pool during the TOGA Coupled Ocean-Atmosphere Response Experiment. J. Climate, 9, 1959-1990.

Yu, J.-Y. and C. R. Mechoso. 1999. Links between annual variations of Peruvian stratocumulus clouds and of SST in the eastern equatorial Pacific. J. Climate, 12, 3305-3318.

Zhurbas, V. and I. S. Oh. 2003. Lateral diffusivity and Lagrangian time scales in the Pacific Ocean as derived from drifter data. J. Geophys. Res., 108, 3141, doi:10,1029/2002JC001596.

2004. Drifter-derived maps of lateral diffusivity in the Pacific and Atlantic Oceans in relation to surface circulation patterns. J. Geophys. Res., 109, C05015, doi:10,1029/2003JC002241. 